\title{
Multi-Objective Optimization of Properties of Sponge Gourd-Bagasse Hybrid Reinforced Polymer Composite Using Fuzzy Logic, PSO, Modified Desirability Function and NSGA II
}

Ikechukwu Chibueze

Nnamdi Azikiwe University

Chizoba Obele

Nnamdi Azikiwe University

CHIDOZIE NWOBI-OKOYE ( $\nabla$ cc.nwobiokoye@coou.edu.ng )

Chukwuemeka Odumegwu Ojukwu University

Clement Atuanya

Nnamdi Azikiwe University

\section{Research Article}

Keywords: Fuzzy logic, Genetic Algorithm, Particle Swarm Optimization, Desirability Function, Composite, Multi objective optimization

Posted Date: July 15th, 2021

DOI: https://doi.org/10.21203/rs.3.rs-678034/v1

License: (9) This work is licensed under a Creative Commons Attribution 4.0 International License.

Read Full License 


\title{
Multi-Objective Optimization of Properties of Sponge Gourd-Bagasse Hybrid Reinforced Polymer Composite Using Fuzzy Logic, PSO, Modified Desirability Function and NSGA II
}

\author{
Ikechukwu G. Chibueze ${ }^{1}$, Chizoba M. Obele ${ }^{2}$, Chidozie C. Nwobi-Okoye ${ }^{3 *}$, Clement U. Atuanya ${ }^{4}$ \\ ${ }^{1}$ Department of Materials and Metallurgical Engineering, Nnamdi Azikiwe University, Nigeria \\ ${ }^{2}$ Department of Polymer and Textile Engineering, Nnamdi Azikiwe University, Nigeria \\ ${ }^{3}$ Faculty of Engineering, Anambra State University (Chukwuemeka Odumegwu Ojukwu University), Uli, Nigeria \\ ${ }^{4}$ Department of Materials and Metallurgical Engineering, Nnamdi Azikiwe University, Nigeria \\ * Corresponding author's emails: cc.nwobiokoye@ coou.edu.ng, chidozien@yahoo.com
}

\begin{abstract}
Development of mathematical models for prediction of properties of materials is often complex and cumbersome. This led to the advent of simpler, and often more accurate, computational models based on artificial intelligence for predicting materials properties. The aim of this study is to predict the mechanical properties of a newly developed hybrid composite material made with sponge gourd, baggase and epoxy resin for golf club application using fuzzy logic (FL) and carry out a multi-objective optimization of the properties with modified desirability function (DF) and NSGA II algorithm. The inputs were $\% \mathrm{Wt}$ of baggase, $\% \mathrm{Wt}$ of Sponge gourd and Fiber size $(\mu \mathrm{m})$ while the response variables were tensile strength, hardness, flexural strength, modulus, elongation and impact strength. The FL model was separately coupled, as fitness function, with the modified DF algorithm and the NSGA II algorithm respectively. The DF was optimized with particle swarm optimization (PSO) algorithm. The results showed that the FL model predicted the mechanical properties accurately and the minimum correlation coefficient $(\mathrm{R})$ between the experimental responses and FL predictions was 0.9529 . The modified algorithms took care of certain peculiarities in the desirability properties such as elongation whose desirability is constant over a range. The optimized properties were found to be worse if the optimization algorithms were not modified.
\end{abstract}

Keywords: Fuzzy logic; Genetic Algorithm; Particle Swarm Optimization; Desirability Function; Composite; Multi objective optimization

\subsection{Introduction}

Artificial intelligence (AI) is currently gaining traction in all fields of human endeavour. Modern applications of AI can be broadly categorized into three namely: clustering, prediction and classification. One of the most extensive uses of AI in science and engineering is in prediction. Prediction applications range from materials properties prediction, prediction 
of chemical process outputs, prediction of industrial processes outputs etc. Often prediction models whether mathematical or computational are sought because experiments are expensive to conduct $[1,2,3]$.

Development of excellent prediction and optimization models for materials science and engineering applications is critical for advances in modern engineering. Hence, extensive researches are currently geared towards this direction with AI leading the charge $[4,5,6,7]$. There are several AI tools used in science and engineering which include but not limited to Artificial Neural Networks (ANN), Adpative Neuro-Fuzzy Inference System (ANFIS), Fuzzy Logic (FL), Genetic Algorithm (GA), Particle Swarm Optimization (PSO) etc [8, 9, 10, 11, 12, 13]. In this present application, Fuzzy Logic, Non Dominated Sorting Genetic Algorithm (NSGA II) and Particle Swarm Optimization were used for prediction and multi objective optimization of properties of a newly developed hybrid composite for golf club application.

The literature is replete with several applications of AI to prediction and optimization of materials properties [3, 14, 15, 16, 17, 18, 19]. Nwobi-Okoye et al. [8] used ANN, ANFIS and NSGA II for multi objective optimization of properties of Aluminum Alloy A356/Cow Horn Particulate Composite subjected to age hardening. They successfully optimized hardness and cost as function of composition, temperature and age hardening time. Their findings showed that ANFIS was less effective than ANN as a fitness function for the NSGA II optimization algorithm. Nwobi-Okoye et al [9] used NSGA II algorithm combined with ANN as its fitness function to carry out multi objective optimization of dry compressive strength of groundnut shell ash particles and ant hill bonded foundry sand. The optimization objectives were maximization of compressive strength and minimization of cost of mould production. The Pareto front obtained from the NSGA II algorithm showed the optimum strength and cost achievable with corresponding process input variables. Chowdhury et al. [20] used fuzzy logic for the prediction and optimization of erosion rate of carbon fiberreinforced ebonite. They used experimental data to develop a fuzzy logic model for predicting the erosion rate in response to variations in impact velocity, impingement angle, erodent size, and stand-off distance. The results showed that the fuzzy logic model predicted the experimental results with an accuracy of $94.45 \%$. Sinha et al. [1] used fuzzy logic for the prediction of the mechanical properties of hybrid abaca-reinforced polymer composite. The input variables for the prediction model were weight per cent of abaca fibre, particle size of red mud and weight per cent of red mud while the output parameters were tensile strength and flexural strength. The results showed that the validated model had a prediction accuracy of $87 \%$. Umeonyiagu and Nwobi-Okoye [10] used ANN and NSGA II for multi objective optimization of bamboo reinforced concrete beams. The objectives of their optimization were minimization of cost and maximization of tensile and flexural strengths of the concrete beams. The input parameters were percentage bamboo composition and age hardening days. Their findings showed that optimization results would serve as an excellent guide in designing strong and cost effective concrete beams reinforced with bamboo. Nwobi-Okoye and Uzochukwu [11] carried out multi objective optimization of Al 631/Egg shell metal matrix composite material produced through stir casting process using NSGA II algorithm which used ANN as its fitness function. the optimization objectives were minimization of 
hardness and maximization of toughness. The optimization results expanded effectively the applicability of $\mathrm{Al}$ 631/Egg shell metal matrix composite materials in areas where ductility is of utmost importance. Nwobi-Okoye et al. [12] used NSGA II algorithm coupled with ANN based prediction model as objective function for multi objective optimization of particle boards produced from recycled high density polyethylene and newboldia laevies fibres. The properties optimized were modulus of rupture, modulus of elasticity, internal bonding, thickness swelling and water absorption. The results showed that the optimized composite materials could be used extensively for the production of high quality particle boards for domestic and industrial use. Tarasov et al. [21] applied fuzzy logic based prediction model for modelling of yield strength of as-cast A356 alloy. They developed two fuzzy logic models to model the relationship between yield strength against chemical composition and the rate of solidification of cast A356 alloy. Their findings showed that the models had very good prediction accuracy with prediction errors of $3.53 \%$ and $3.19 \%$ respectively. Aamir et al. [22] used Taguchi Method and Fuzzy Logic to model and optimize the Process Parameters in Multi-Hole Simultaneous Drilling. The results showed that the Taguchi optimization, optimal drilling parameters occur at a low cutting speed and feed rate using a poly-drill head. The results of the fuzzy logic model which was used to predict the surface roughness and hole size were found to be in good agreement with the experimental values.

Having looked at the literature above, this study is unique because it used a specially modified desirability function, optimized with PSO coupled with a fuzzy logic model as its fitness function, as well as a modified NSGA II algorithm coupled with a fuzzy logic prediction model as its fitness function for multi objective optimization of a newly developed hybrid polymer composite material made with sponge gourd, bagasse and epoxy resin.

\subsection{Methodology}

\subsection{Composite Material Production}

\subsubsection{Materials}

The baggase fiber used in the work as shown in Figure 1 was obtained from the local market in Awka, Nigeria while the sponge gourd as shown in Figure 2 was sourced locally from the bush. The epoxy resin and the hardener used were bought from the local market. 


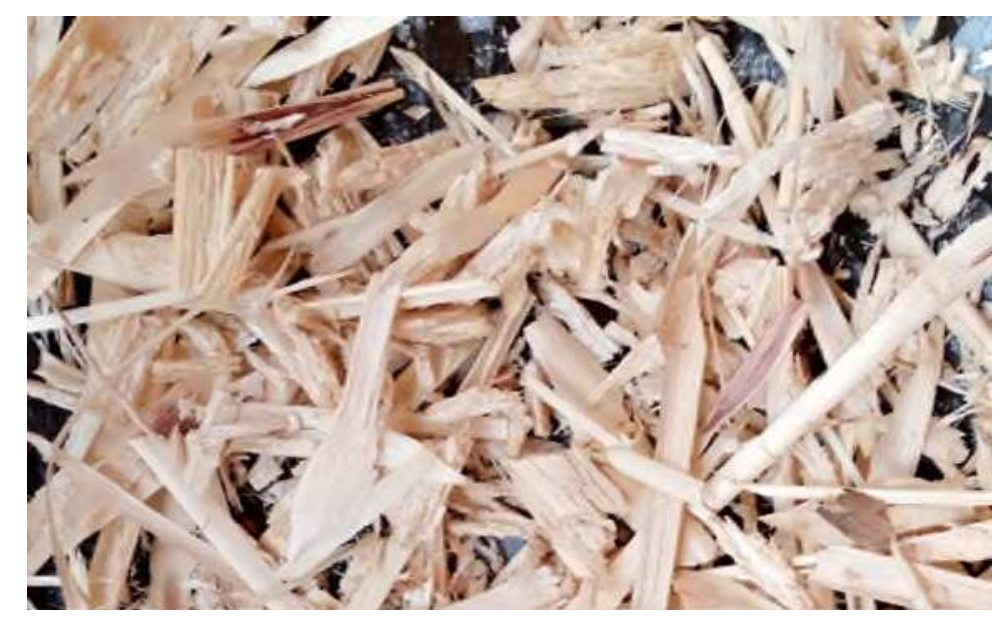

\section{Figure 1: Unreated baggase fiber}

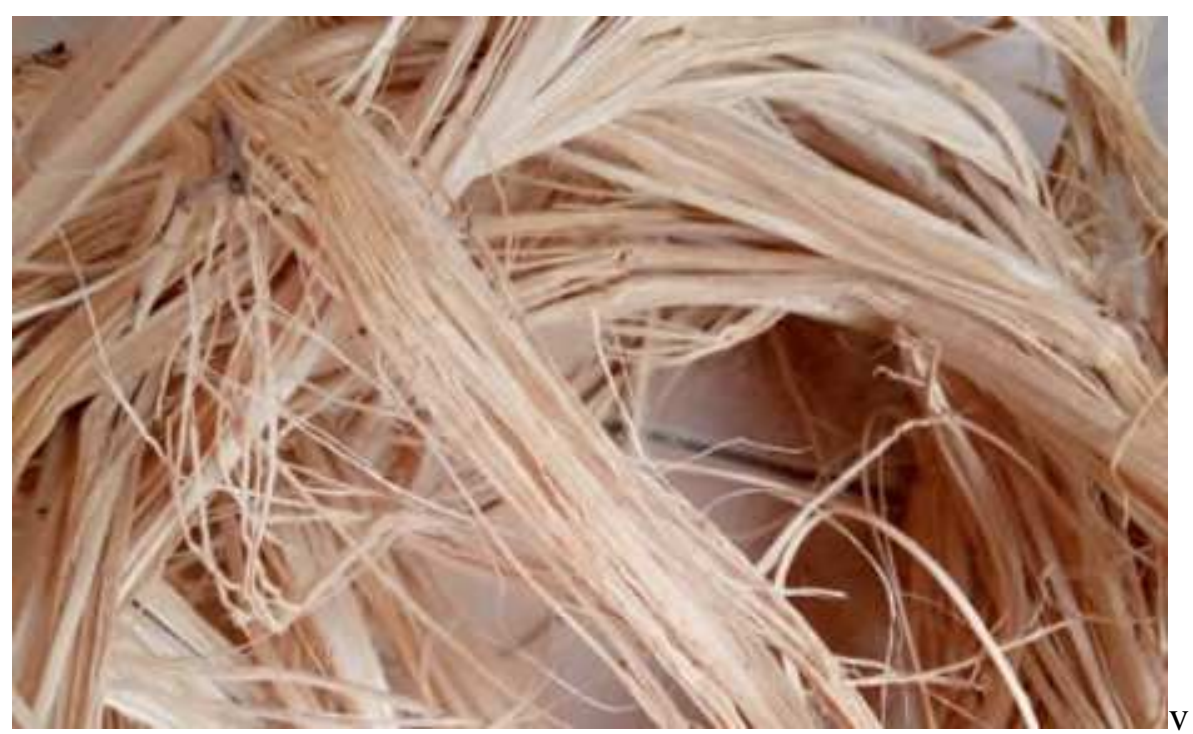

Figure 2: Untreated Sponge gourds Fiber

\subsubsection{Preparation of the baggase and sponge gourd fiber.}

The baggase and sponge gourd fibers are prepared separately and independently. The baggase was soaked in water for $24 \mathrm{hrs}$ so as to remove any dirt or debris in the fiber and sun dried for 2 days, thereafter the dried bagasse was soaked in $10 \%$ concentration $\mathrm{NaOH}$ solution for 24hrs (Figure 3) in other to remove lignin, wax and other impurities from the fiber, hence increasing the fiber roughness and adhesiveness. The alkaline treated fiber was therefore continually rinsed with water until a $\mathrm{pH}$ value of 7 is obtained so as to obtain a neutral solution (fiber). The rinsed fiber is sun dried again for 2 days before subjecting to methanol treatment where the fiber is soaked in a dilute methanol solution (60:40) for $3 \mathrm{hrs}$ which help in further increasing the fiber roughness and bonding properties of the fiber as shown in Figure 4. The methanol treated fiber was therefore sun dried for 2 days thereafter 
making the fiber ready for pulverization. These procedures were also repeated for preparation of sponge gourd fiber.
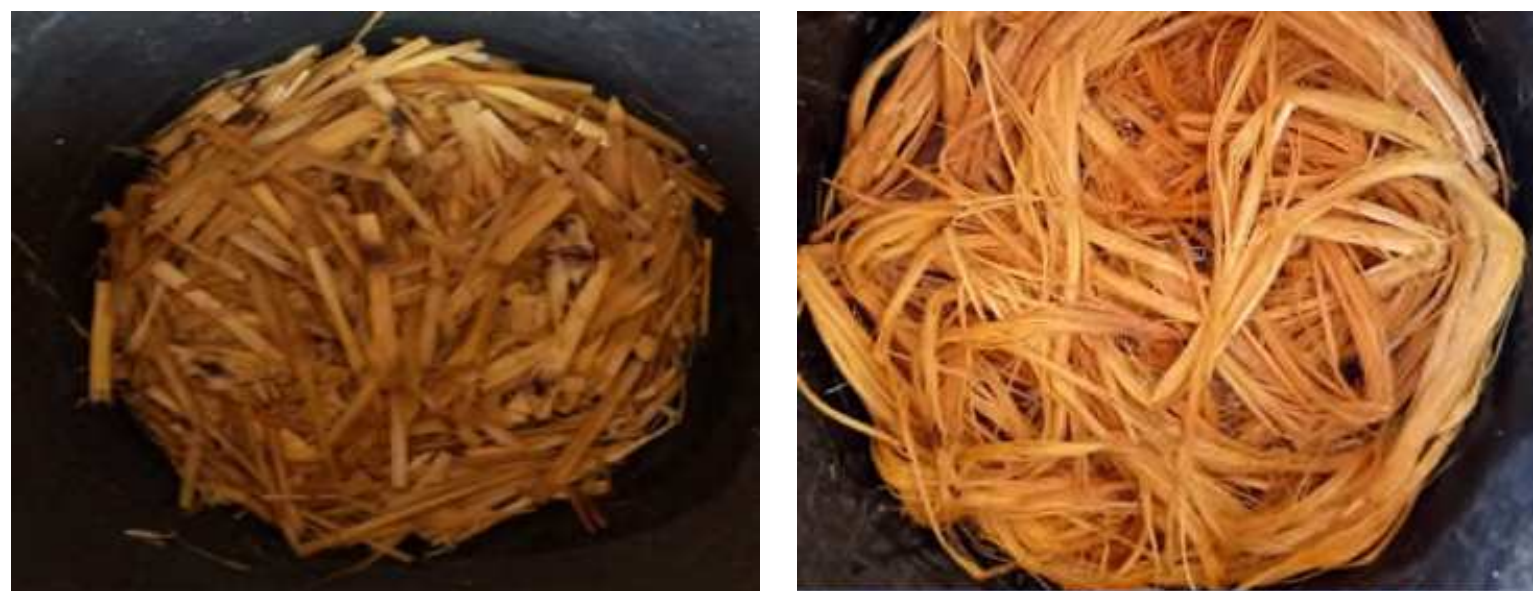

Figure 3: Treatment of the fiber using dilute $\mathrm{NaOH}$ solution
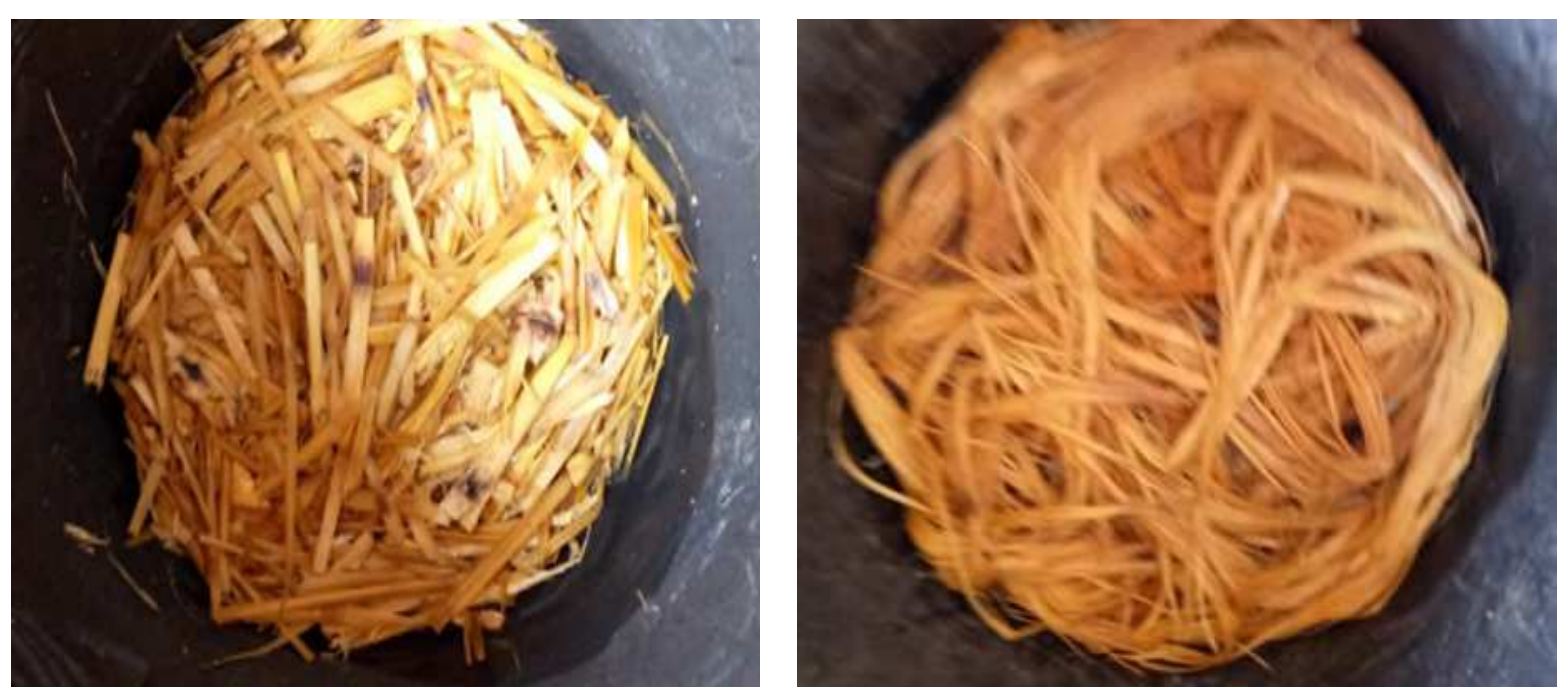

Figure 4: Treatment of the fiber using dilute methanol solution

\subsubsection{Particle size analysis}

The surface areas of the fibers (baggase and sponge gourd) were increased by pulverization technique, which convert the long grain fibers to a powdered form as shown in Figure 5. 


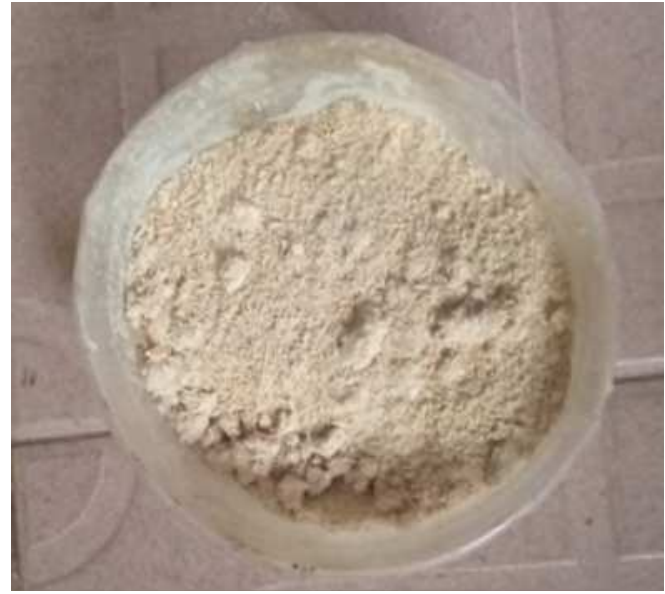

(a). Pulverized baggase fiber

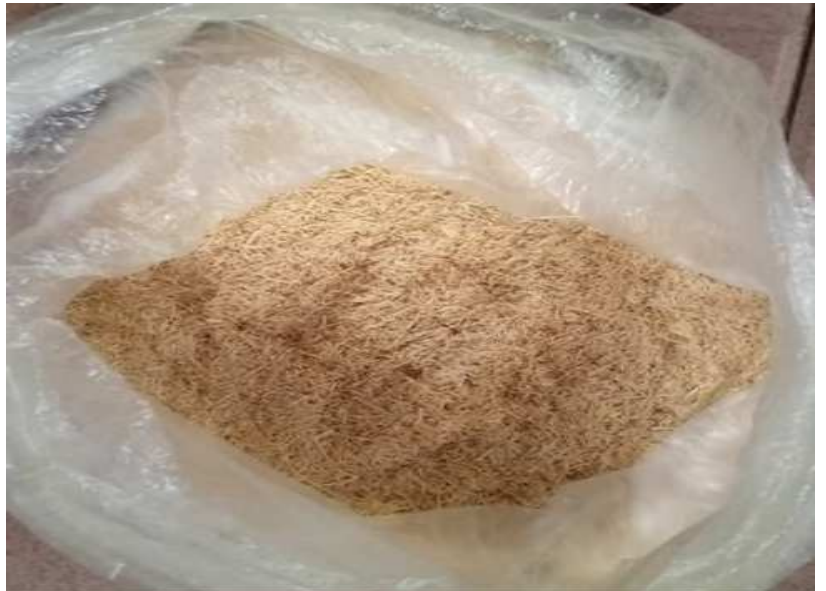

(b). Pulverized sponge gourd fiber

\section{Figure 5: Pulverized fibers}

The particle size analysis of the pulverized fibers was carried out in accordance with ASTM60. $200 \mathrm{~g}$ of the fiber particles were placed into a set of sieves arranged in descending order of fineness and electrically shaken for 15 minutes which is the recommended time to achieve complete classification as shown in Figure 6. The weight retained on $150 \mu \mathrm{m}, 300 \mu \mathrm{m}$ and $600 \mu \mathrm{m}$ were used in this research.

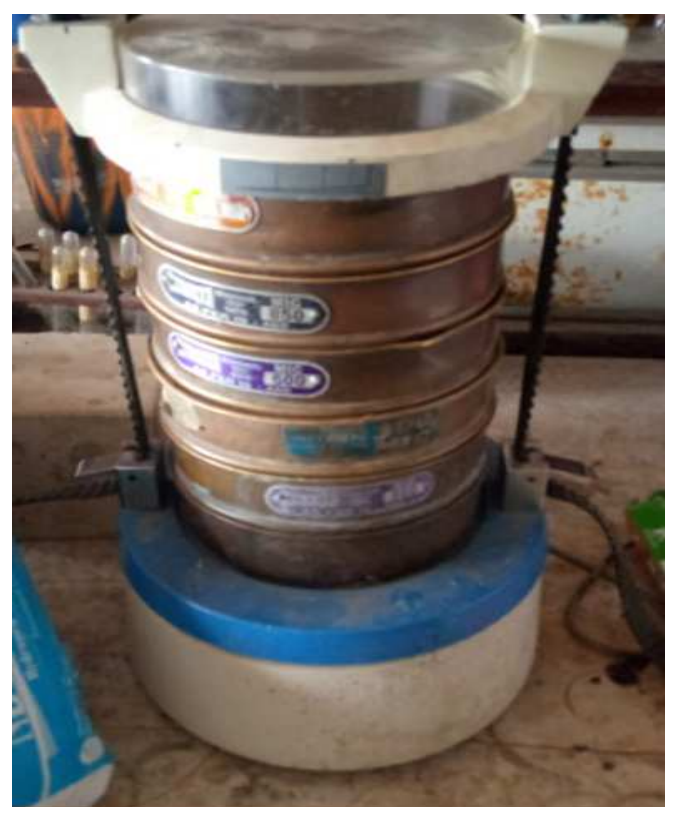

Figure 6: Electronic sieving Machine

\subsubsection{Composite Sample Production.}


The wt $\%$ of the fibers (baggase and sponge gourd), polymer were measured accordingly via an air tight electronic weighing balance (Figure 7) using the data analysis obtained from the design of experiment using Taguchi.

Heating of the paraffin wax to its melting point $\left(50^{\circ} \mathrm{c}\right)$ was done with the help of a Bunsen burner; thereafter the liquid wax was immediately sprinkled on the metal mould before casting. This is done for easy removal of the samples from the metal mould. After waxing the mould, the composite materials (wt\% of baggase, \%wt of sponge gourd, polymer and hardener) are mixed in a crucible plate and stirred continuously using a stirrer until a uniform mixture is obtained.

The mixture was therefore poured into a $300 \mathrm{~mm} \times 300 \mathrm{~mm}$ waxed metal mould and allowed to set; the design formation from Table 5 was used in the production of the composite.

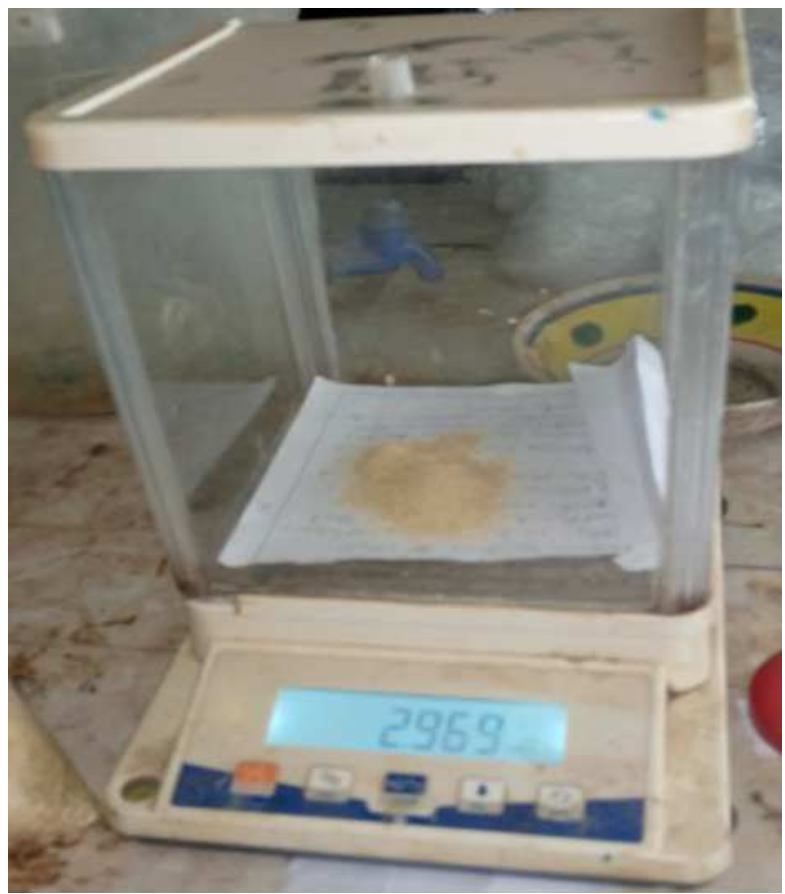

\section{Figure 7: Electronic weighing Machine}

\subsubsection{Design of Experiment}

The design of the experiment was done via Taguchi robust design which involves reducing the variation in a process through robust design of experiments. Classical experimental design methods are too complex and are not easy to use. A large number of experiments have to be carried out when the number of process parameters increase. To solve this problem, the Taguchi method uses a special design of orthogonal arrays to study the entire parameter space with only a small number of experiments. Three superplastic forming parameters are considered as controlling factors. They are \%wt of fiber 1 (bagasse), \% wt of fiber 2(sponge 
gourd) and fiber particle size (Chibueze, 2021). Each parameter has three levels - namely low, medium and high, denoted by 1, 2 and 3 respectively (Chibueze, 2021).

Orthogonal arrays are special standard experimental design that requires only a small number of experimental trials to find the main factors effects on output. Before selecting an orthogonal array, the following step must be followed (Chibueze, 2021).

Step 1: Consider the factors with three various levels. The factors and levels are as shown in Table 1.

Table 1: Factors and there levels

\begin{tabular}{|l|l|}
\hline FACTOR & LEVEL \\
\hline Wt\% of baggase $(\mathrm{A})$ & 3 \\
\hline Wt\% of sponge gourd $(\mathrm{B})$ & 3 \\
\hline Fiber size $(\mathrm{C})$ & 3 \\
\hline
\end{tabular}

Step 2: Determine the degree of freedom (D.O.F).

DOF refers to the number of ways a system can independently vary when a constraint is imposed. The degree of freedom (D.O.F) is shown in Table 2.

Table 2: Degree of freedom (D.O.F)

\begin{tabular}{|l|l|l|}
\hline FACTORS & LEVEL $(\mathrm{S})$ & D.O.F $=\mathrm{S}-1$ \\
\hline $\mathrm{A}$ & 3 & 2 \\
\hline $\mathrm{B}$ & 3 & 2 \\
\hline $\mathrm{C}$ & 3 & 2 \\
\hline $\mathrm{A} \times \mathrm{B}$ & & $2 \times 2=4$ \\
\hline $\mathrm{A} \times \mathrm{C}$ & & $2 \times 2=4$ \\
\hline $\mathrm{B} \times \mathrm{C}$ & & $2 \times 2=4$ \\
\hline & & D.O.F $=18$ \\
\hline
\end{tabular}

Step 3: The total number of experimental runs

$\mathrm{T}_{\text {experiment }}=1+$ D.O.F $=1+18=19$

STEP 4: We select the suitable orthogonal array which must be greater than or equal to 19

Thus referring to the standard orthogonal array table, the nearest orthogonal array is $\mathrm{L}_{27}$.

Step 5: Visualize the required linear graph (RLG) as shown in Figure 8 


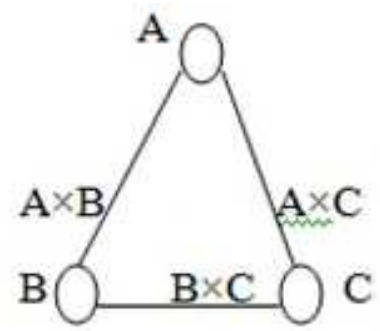

Figure 8: Required linear graph for $\mathrm{L}_{27}$

STEP 6: Compare the Required linear graph and standard linear graph for $\mathrm{L}_{27}$ as shown in Figure 9.
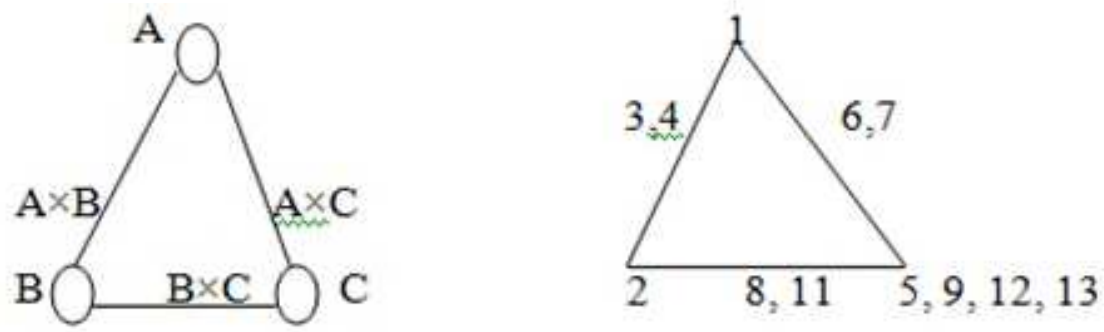

Figure 9: Required linear graph and standard linear graph for $\mathbf{L}_{27}$

Step 7: allocate the factors to the column of the orthogonal array as shown in Table 3.

Table 3: Factors with node assigned

\begin{tabular}{|l|l|}
\hline Factors & Column/node assigned \\
\hline $\mathrm{A}$ & 1 \\
\hline $\mathrm{B}$ & 2 \\
\hline $\mathrm{C}$ & 5 \\
\hline $\mathrm{A} \times \mathrm{B}$ & 3,4 \\
\hline $\mathrm{B} \times \mathrm{C}$ & 8,11 \\
\hline $\mathrm{A} \times \mathrm{C}$ & 6,7 \\
\hline
\end{tabular}

STEP 8: We chose the experimental layout referring to the default orthogonal array design layer as shown in Table 4.

Table 4: Default orthogonal array

\begin{tabular}{|l|l|l|l|}
\hline FACTOR & Level1 & Level 2 & level 3 \\
\hline Wt\% of baggase (A) & $5 \mathrm{wt} \%$ & $10 \mathrm{wt} \%$ & $20 \mathrm{wt} \%$ \\
\hline
\end{tabular}




\begin{tabular}{|l|l|l|l|}
\hline Wt\% of sponge gourd (B) & $5 \mathrm{wt} \%$ & $10 \mathrm{wt} \%$ & $20 \mathrm{wt} \%$ \\
\hline Fiber size $(\mathrm{C})$ & $150 \mu \mathrm{m}$ & $300 \mu \mathrm{m}$ & $600 \mu \mathrm{m}$ \\
\hline
\end{tabular}

The number of experimental runs with their parameters is as shown in Table 5. As shown in Table 5, the number of experiments conducted based on the prescriptions of Taguchi experimental design was 27.

Table 5: Number of experimental runs with their parameters and data

\begin{tabular}{|l|l|l|l|l|l|l|l|l|l|}
\hline \multicolumn{9}{|c|}{ FACTORS } & \multicolumn{3}{c|}{ RESPONSE } \\
\hline s/n & $\begin{array}{l}\text { \%wt } \\
\text { bagasse }\end{array}$ & $\begin{array}{l}\text { S.G } \\
\text { S.G }\end{array}$ & $\begin{array}{l}\text { Fiber } \\
\text { size } \\
(\mu \mathrm{m})\end{array}$ & $\begin{array}{l}\text { Tensile } \\
\text { strength }\end{array}$ & Hardness & $\begin{array}{l}\text { Flexural } \\
\text { strength }\end{array}$ & $\begin{array}{l}\text { Flexural } \\
\text { modulus }\end{array}$ & Elongation & $\begin{array}{l}\text { Impact } \\
\text { strength }\end{array}$ \\
\hline 1 & 5 & 5 & 600 & & & & & & \\
\hline 2 & 10 & 5 & 600 & & & & & & \\
\hline 3 & 20 & 5 & 600 & & & & & & \\
\hline 4 & 5 & 10 & 600 & & & & & & \\
\hline 5 & 10 & 10 & 600 & & & & & & \\
\hline 6 & 20 & 10 & 600 & & & & & & \\
\hline 7 & 5 & 20 & 600 & & & & & & \\
\hline 8 & 10 & 20 & 600 & & & & & & \\
\hline 9 & 20 & 20 & 600 & & & & & & \\
\hline 10 & 5 & 5 & 300 & & & & & & \\
\hline 11 & 10 & 5 & 300 & & & & & \\
\hline 12 & 20 & 5 & 300 & & & & & \\
\hline 13 & 5 & 10 & 300 & & & & & & \\
\hline 14 & 10 & 10 & 300 & & & & & & \\
\hline 15 & 20 & 10 & 300 & & & & & & \\
\hline 16 & 5 & 20 & 300 & & & & & & \\
\hline 17 & 10 & 20 & 300 & & & & & & \\
\hline 18 & 20 & 20 & 300 & & & & & & \\
\hline 19 & 5 & 5 & 150 & & & & & & \\
\hline 20 & 10 & 5 & 150 & & & & & & \\
\hline 21 & 20 & 5 & 150 & & & & & & \\
\hline 22 & 5 & 10 & 150 & & & & & & \\
\hline 23 & 10 & 10 & 150 & & & & & & \\
\hline 24 & 20 & 10 & 150 & & & & & & \\
\hline 25 & 5 & 20 & 150 & & & & & & \\
\hline 26 & 10 & 20 & 150 & & & & & \\
\hline 27 & 20 & 20 & 150 & & & & & \\
\hline
\end{tabular}

\subsubsection{Composite Testing Procedure}

The properties that were tested are density, tensile strength, hardness, modulus, flexural strength, elongation and impact strength.

\subsubsection{Density}


The density of the composite was obtained from mathematical expressions and calculations after pouring the composite into a small graduated cylinder with known volume.

Let volume of the cylinder $=\mathrm{V}$

Mass of cylinder $=$ M1

Mass of cylinder + composite $=\mathrm{M} 2$

Therefore ,

Mass of composite M3 = M2 - M1.

Thus;

Density of composite $=$ mass $/$ volume

Density $=\frac{M 3}{V}$

\subsubsection{Flexural Test}

Prior to the test, all the samples were conditioned at a temperature of $25^{\circ} \mathrm{c}$ and relative humidity of 65\% according to ASTM D618-08(Rotton, 1999). Test samples were made according to the recommended standard for flexural testing. Flexural test was performed on a M500-25CT testometric testing machine at Civil Engineering, Material Laboratory of University of Nigeria, Nssuka (Figure 10).

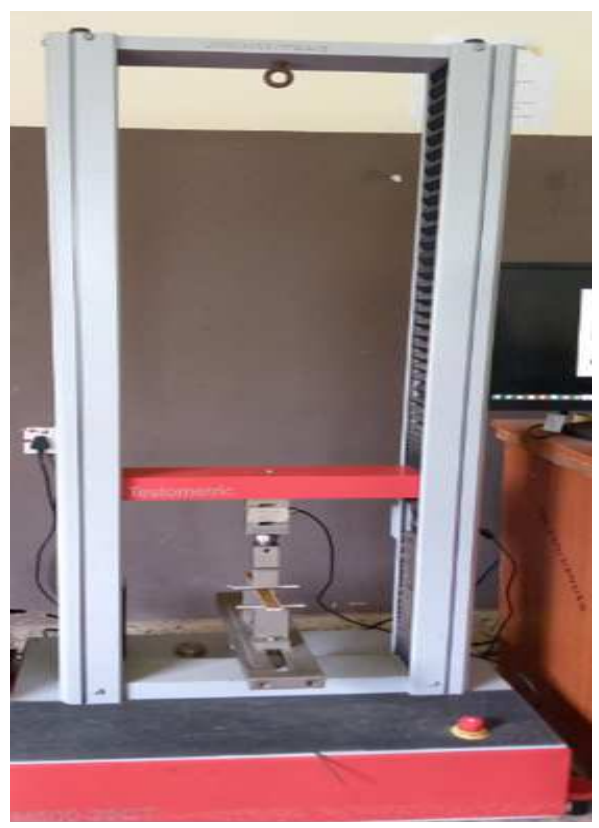

Figure 10: M500-25CT testometric testing machine

A three point bending configuration was used with specimen nominal dimension of $200 \mathrm{~mm}$ $\times 20 \mathrm{~mm} \times 5 \mathrm{~mm}$. the load was applied continuously throughout the test at a uniform rate of $50 \mathrm{~mm} / \mathrm{min}$. 
The flexural strength was determined in accordance with ASTM D790- 10 standard test method. The flexural strength was calculated for each specimen in accordance with the following equations.

$\mathrm{R}_{\mathrm{b}}=\frac{3 \mathrm{P}_{\max } \mathrm{L}}{2 \mathrm{bd}^{2}}$

Where

$\mathrm{b}=$ width of specimen measured in dry condition $(\mathrm{mm})$

$\mathrm{d}=$ thickness of span in $\mathrm{mm}$

$\mathrm{P}_{\max }=\operatorname{maximum} \operatorname{load}(\mathrm{N})$.

\subsubsection{Tensile Strength}

The tensile strength measurement experiment was performed on a testometric testing machine at University of Lagos, Nigeria.

For the tensile test, the composite samples were $160 \mathrm{~mm} \times 20 \mathrm{~mm} \times 4 \mathrm{~mm}$ in dimension in accordance with ASTM 638-10 standard test method for tensile properties of polymer. The tests were performed at a constant strain rate of $0.5 \mathrm{~mm} / \mathrm{min}$. the maximum tensile strength was calculated in accordance with the equation:

$\mathrm{R}_{\mathrm{T}}=\operatorname{Pmax}$

$\mathrm{Bd}$

Where

$\mathrm{B}=$ width of reduced cross section of the specimen measured in dry conditioning $(\mathrm{mm})$

$\mathrm{D}=$ thickness of the specimen measured in dry condition

Pmax = maximum tensile load $(\mathrm{N})$

$\mathrm{R}_{\mathrm{t}}=$ maximum tensile stress $(\mathrm{MPa})$

\subsubsection{Impact Strength Test}

The impact testing of the composite samples were conducted using Avery dension test machine at the department of Metallurgical and Materials Engineering, University of Nigeria, Nsukka, Nigeria (Chibueze, 2021). Charpy impact tests was conducted on the samples with $100 \mathrm{~mm} \times 20 \mathrm{~mm} \times 5 \mathrm{~mm}$ dimension in accordance with ASTM D256-10 standard test method for determining the chary pendulum impact resistance of plastics (Chibueze, 2021). Before the test, samples were mounted on the machine, the pendulum was released to calibrate the machine. The test samples were then gripped horizontally in a vice and the force required to break the bar was released from the freely swinging pendulum. the value of the angle through which the pendulum swung before the test sample was broken correspond with the value of the energy absorbed in breaking the sample and this was read from the calibrated scale on the machine (Chibueze, 2021). 


\subsubsection{Hardness test.}

The hardness testing of the samples was done using leeb hardness tester at the department of Metallurgical and Materials Engineering, University of Nigeria, Nsukka, Nigeria.

Leeb hardness testing was conducted on the samples with $20 \mathrm{~mm} \times 20 \mathrm{~mm} \times 20 \mathrm{~mm}$ according to ASTM A956 standard, prior to the test, the samples were mounted on the anvil as shown in Figure 11, and then the impact device accelerates an impact body using spring force. The velocity of the impact body is broken down into three phases.

1. Approach phase, during which the impact body is accelerated towards the test surface by means of the spring force.

2. Impact phase, during which the impact body and the specimen are in direct contact. The specimen is thereby elastically and plastically deformed and the impact body is brought to a complete standstill. The elastic spring-back of impact body and specimen causes the impact body to rebound.

3. Rebound phase, during which the impact body is again accelerated out of the impact phase with the remaining energy.

Thus, the ratio of rebound velocity $\mathrm{V}_{\mathrm{r}}$ to impact velocity $\mathrm{V}_{\mathrm{i}}$, multiplied by a factor of 1000 gives the leeb hardness.

Ie

$$
\mathrm{HL}=\frac{\text { Rebound velocity }}{\text { Impact velocity }} \times 1000
$$

Thereafter leeb hardness results in HL are converted to traditional hardness scale HR (hardness according to Rockwell) from classified hardness chart.

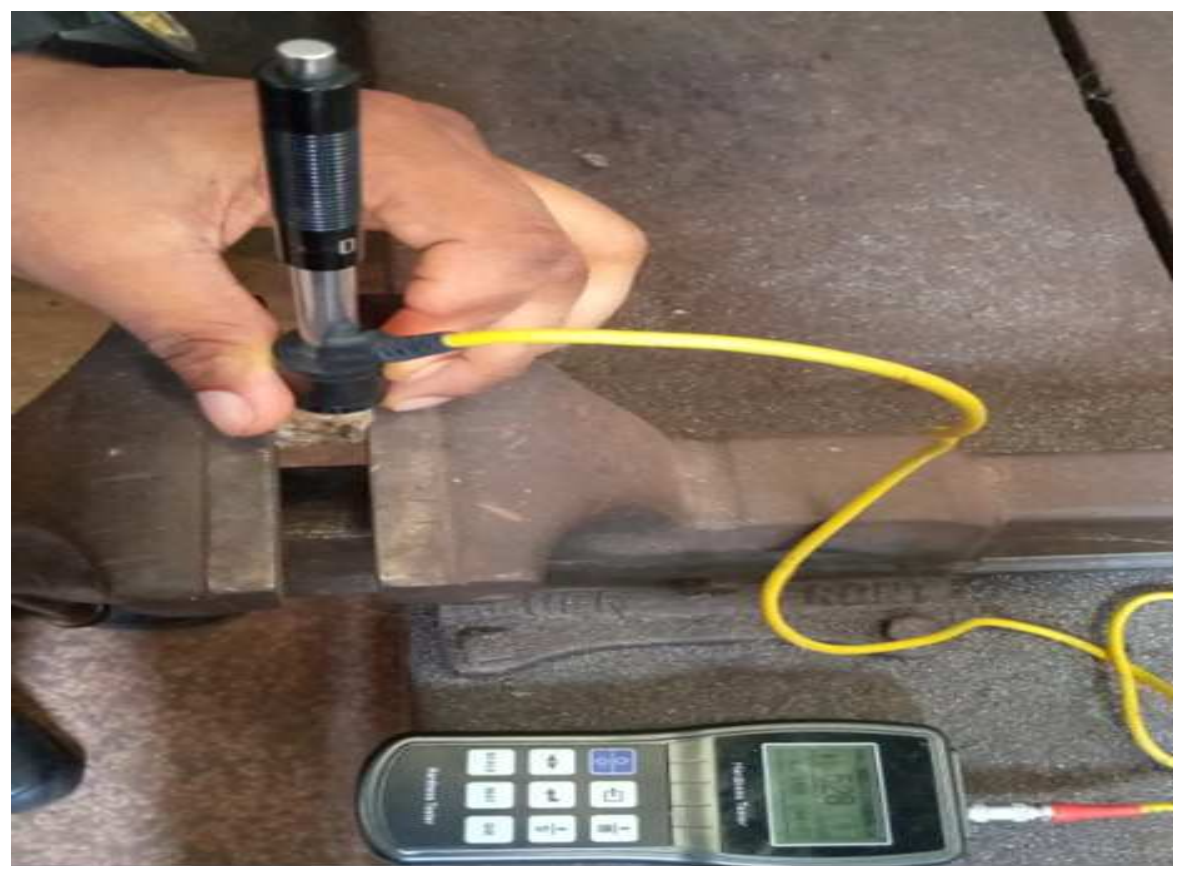

\section{Figure 11: Leeb hardness tester}




\subsubsection{6: Specific strength}

Specific strength is also known as strength to weight ratio. And it is measured as

Specific strength $(\mathrm{Nm} / \mathrm{Kg})=\frac{\text { tensile strength }}{\text { density of the material }}$

\subsubsection{7: Specific Stiffness}

Specific stiffness is also referred to as Modulus to weight ratio, and its represented as:

Specific Modulus $(\mathrm{Nm} / \mathrm{Kg})=\frac{\text { modulus }}{\text { density of the material }}$

\subsection{Fuzzy Logic Modelling}

The experimental data acquired from testing the produced composite material was modeled with fuzzy logic. The input-output data obtained from the experiment described in section 2.1.6 underwent both fuzzification and defuzzification as shown in Figure 12 in order to obtain the fuzzy logic model for prediction of the properties of the composite material.

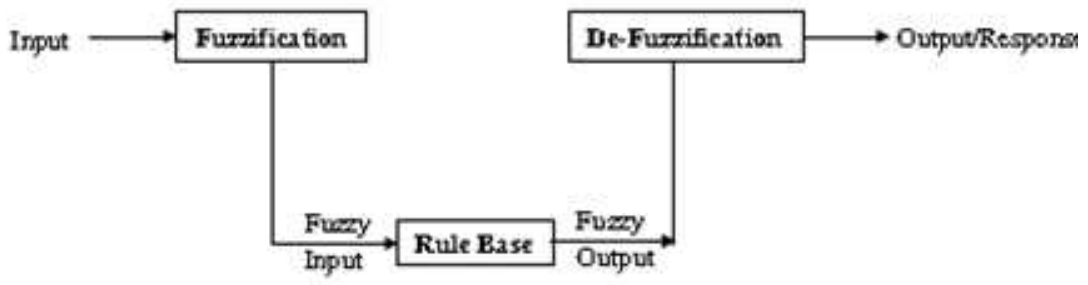

Figure 12: Component of fuzzy system

Figure 13 shows the fuzzy inference system for predicting the mechanical properties of the hybrid composite studied. As shown in Figure 11, \%wt of bagasse, \%wt of sponge gourd and fiber size are inputs to the fuzzy inference system, while the tensile strength, flexural strength, elongation, impact strength, hardness and modulus derived from defuzzification are the output. The membership function for \%wt bagasse, \%wt sponge gourd and fiber size are shown in Figures 14 - 16 respectively. The membership function for \%wt bagasse and \%wt sponge gourd as shown in Figure 14 and 15 consists of five (5) linguistic variables namely: Very low (VL), low (LW), Medium (M), High (H), Very High (VH). The membership function for fiber size shown in Figure 16 consist of 8 variables, namely; FS1, FS2, FS3, FS4, FS5, FS6, FS7, FS8. 


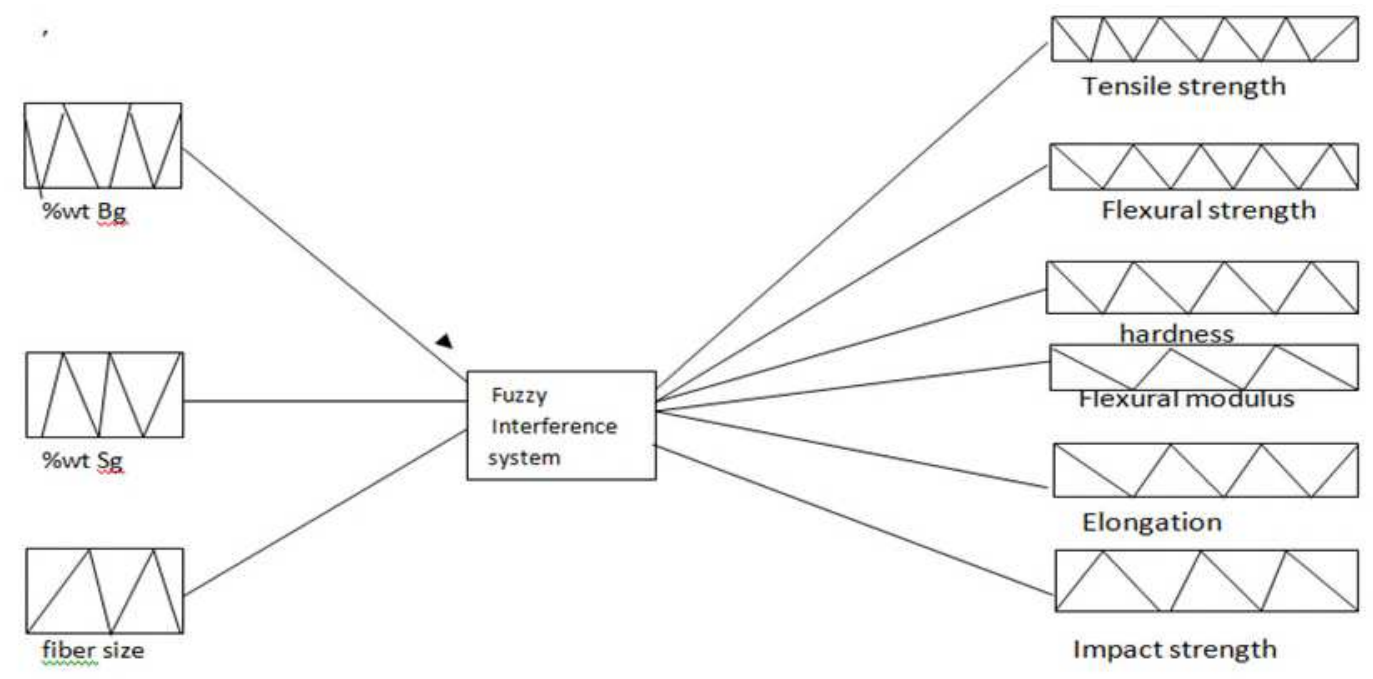

Figure 13: Fuzzy interference system of hybrid composite.

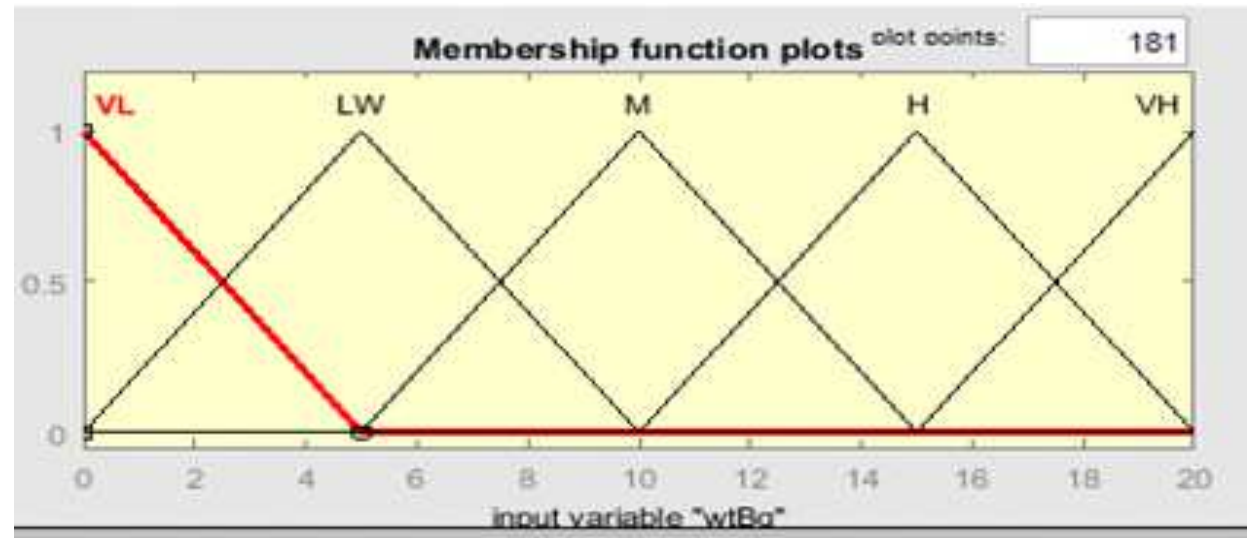

Figure 14: Membership function for \% wt Bagasse

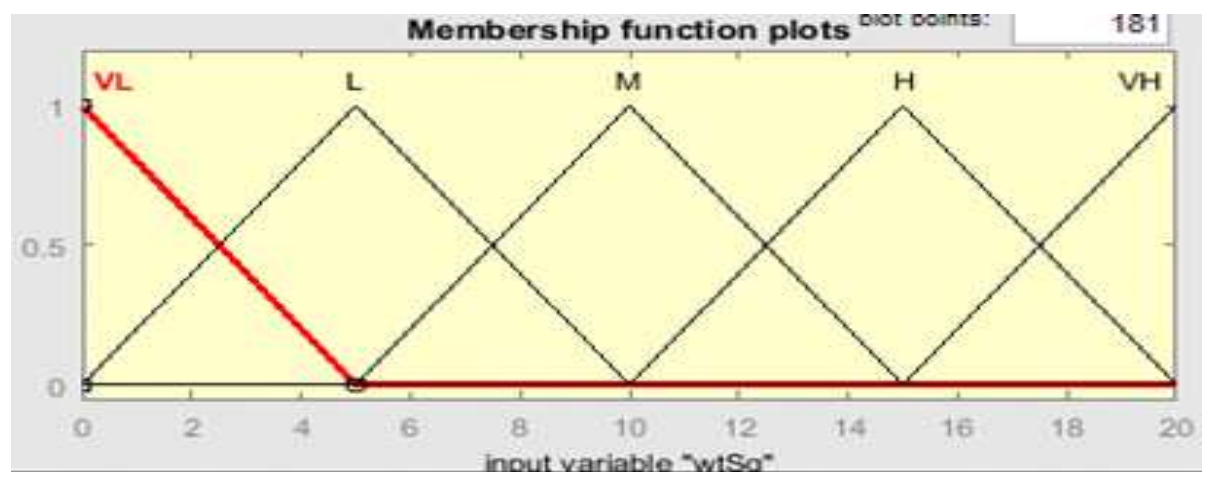

Figure 15: Membership function for \% wt sponge gourd 


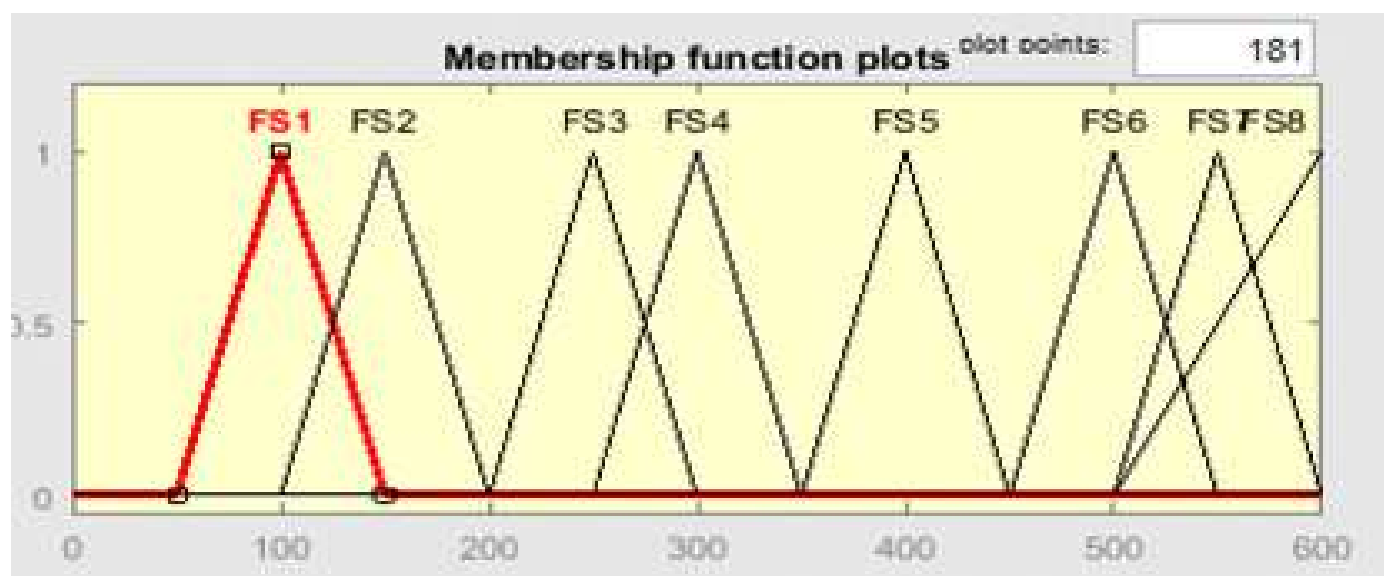

Figure 16: Membership function for the fiber size

Six fuzzy logic models were used in the prediction modeling. Model I has 24 linguistic variables for the output (hardness ) as shown in Figure 17a, model 2 have 49 linguistics for the output flexural strength (Figure 17b), model 3 contain 26 linguistic variables for flexural modulus (Figure 17c), model 4 have 16 variables for elongation (Figure 17d) and model 5 have 26 variables for impact strength (Figure 17e).

The fuzzy logic model generates 27 different rules. The 27 rules were used by the Mamdani fuzzy inference system to predict the mechanical properties (tensile strength, hardness, flexural strength, elongation, impact strength and modulus) after defuzzification using the centroid method. Eighty percent $(80 \%)$ of the experimental data were used to develop the fuzzy logic model while twenty percent (20\%) were used for testing and validation. The results of the fuzzy modeling process are presented in section 3.2.

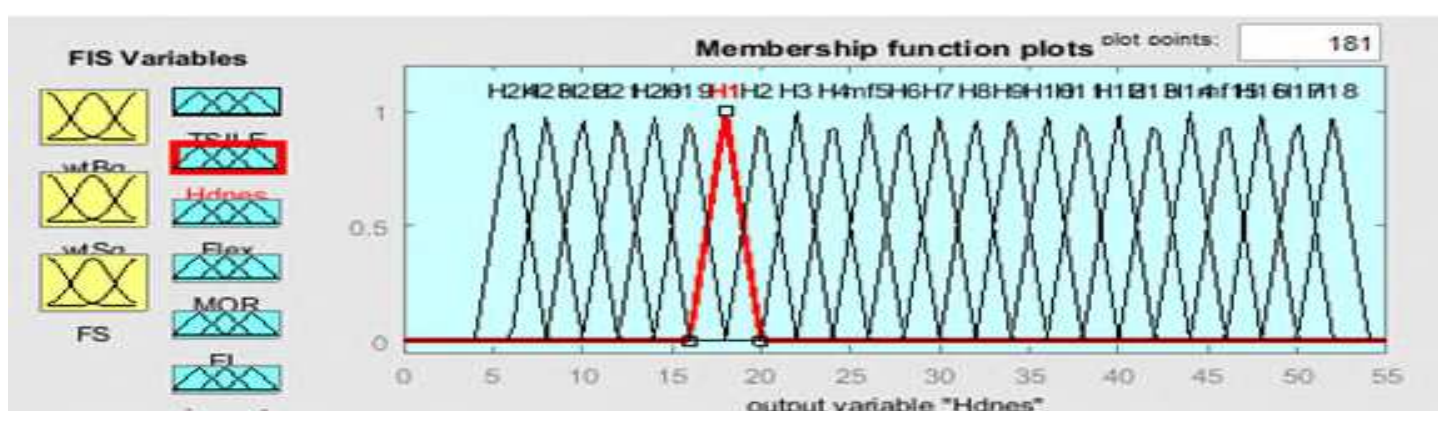

Figure 17a: Membership function for hardness

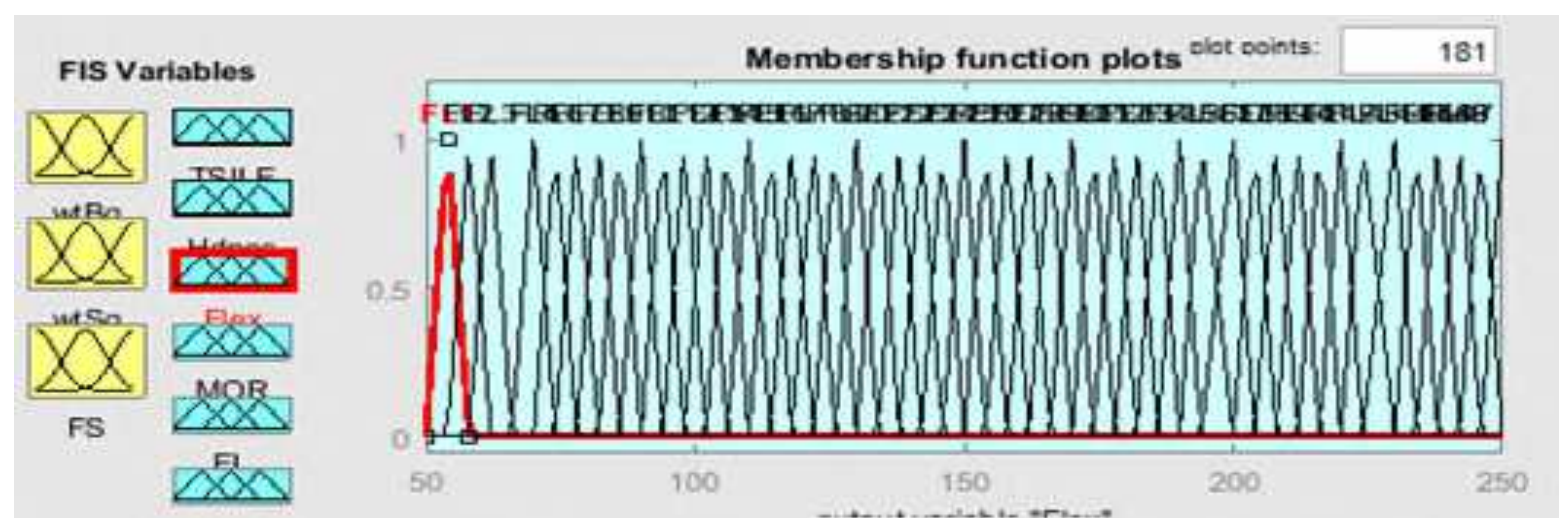


Figure 17b: Membership function for flexural strength

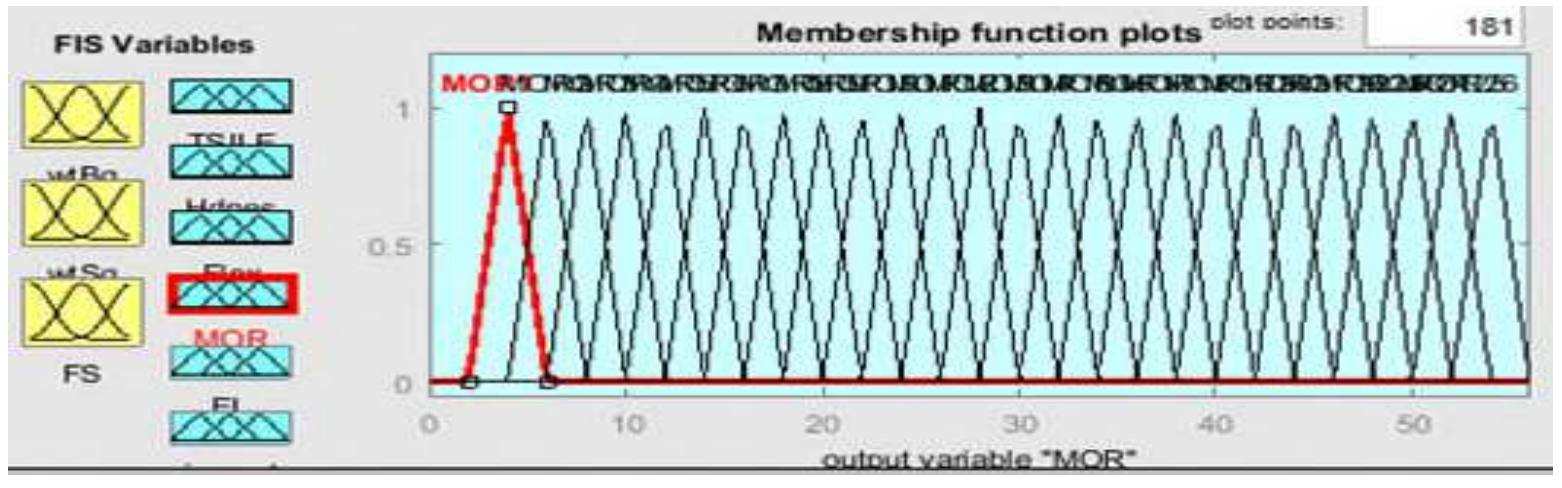

Figure 17c: Membership function for Modulus

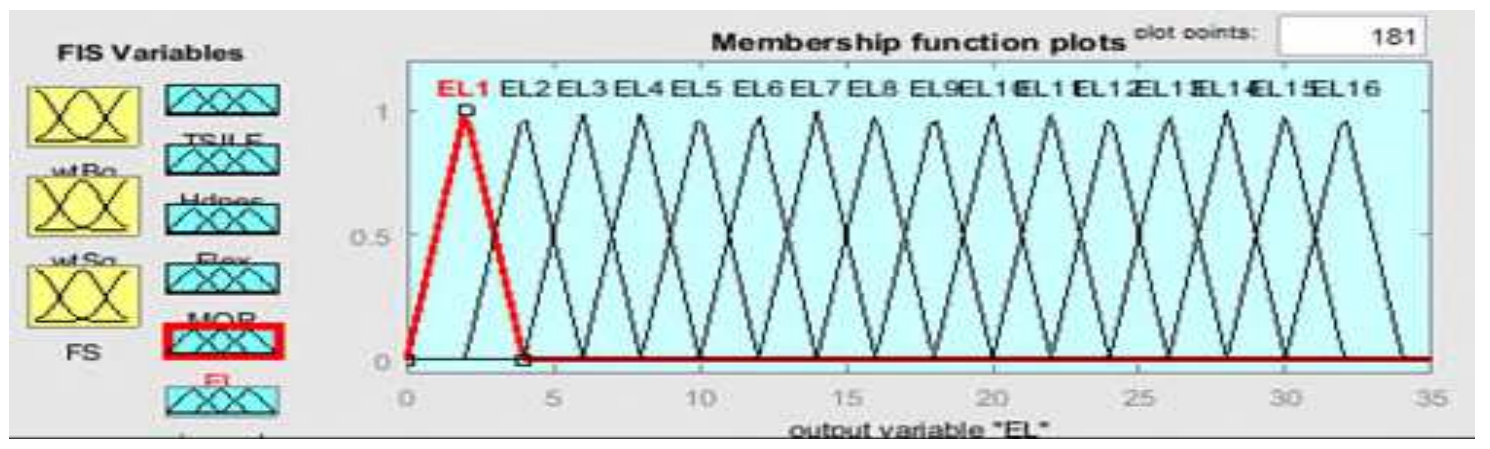

Figure 17d: Membership function for Elongation

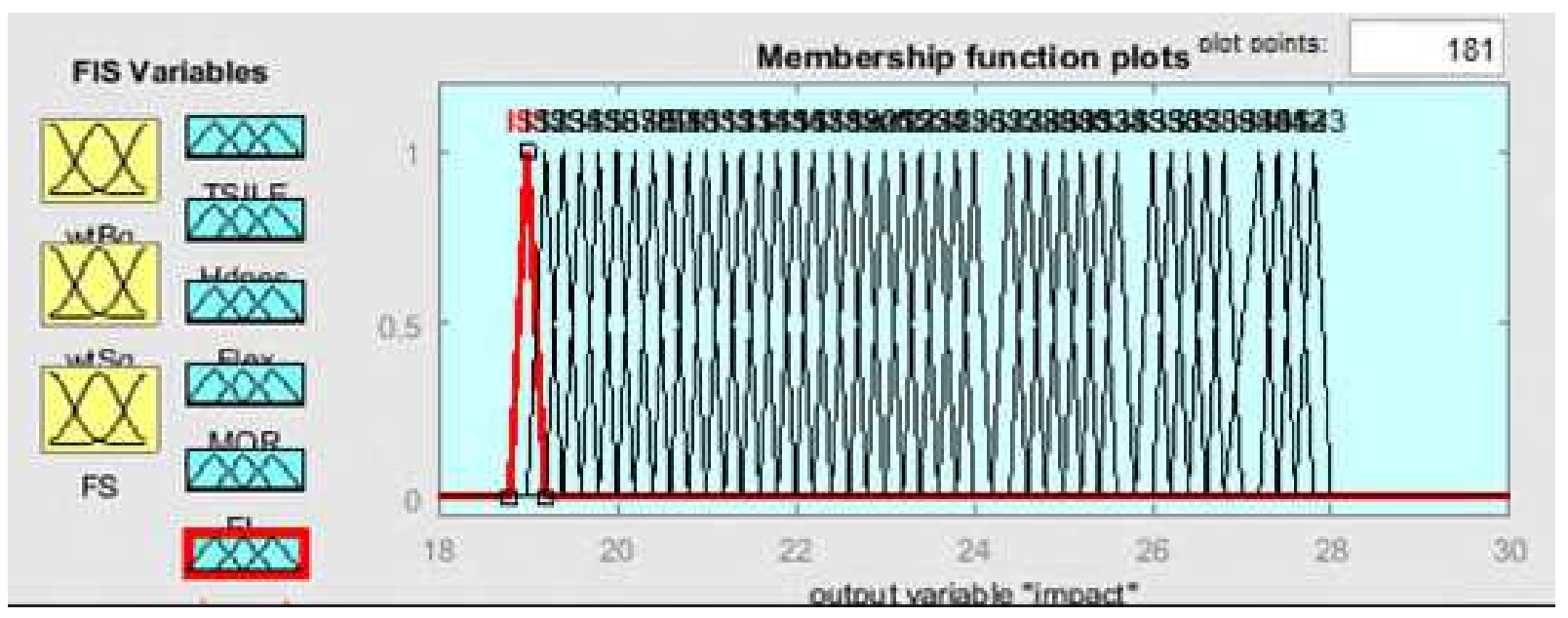

Figure 17e: Membership functions for impact strength.

\subsection{Multi objective Optimization with Desirability Function and NSGA II Algorithm}

\subsubsection{Desirability Function Development}

Desirability function is a popular multi objective optimization tool. The function is such that if the objective is to maximize, the following relationship obtains: 


$$
d i=\left\{\begin{array}{rr}
0 & \hat{y} \leq L i \\
\left(\frac{\hat{y}-L i}{T i-L i}\right)^{s} & L i<\hat{y}<T i \\
1 & \hat{y} \geq T i
\end{array}\right.
$$

Similarly, if the objective is to minimize, the following relationship obtains:

$$
d i=\left\{\begin{array}{rr}
1 & \hat{y} \leq T i \\
\left(\frac{U i-\hat{y}}{U i-T i}\right)^{s} & T i<\hat{y}<U i \\
0 & \hat{y} \geq U i
\end{array}\right.
$$

If it is desired that the response be a target value with an upper and lower limit, the desirability is given as:

$$
\begin{aligned}
& d i=\left(\frac{\hat{y}-L i}{T i-L i}\right)^{s} \quad L i \leq \hat{y} \leq T i \\
& d i=\left(\frac{U i-\hat{y}}{U i-T i}\right)^{s} \quad T i \leq \hat{y} \leq U i \\
& d i=0 \quad \text { if } \hat{y}<L i \\
& d i=0 \quad \text { if } \hat{y}>U i
\end{aligned}
$$

We introduce a new criterion such that if the desirability is constant over a certain interval then the following equation obtains:

$$
\begin{aligned}
& d i=\left\{\begin{array}{lr}
0 & \hat{y} \leq L i \\
1 & L i<\hat{y}<U i \\
0 & \hat{y} \geq U i
\end{array}\right. \\
& d i=\left\{\begin{array}{rr}
\left(\frac{\hat{y}-L i}{T 1 i-L i}\right)^{s} & \hat{y} \leq L i \\
1 & T 1 i<\hat{y}<T 2 i \\
\left(\frac{U i-\hat{y}}{U i-T 2 i}\right)^{s} & \hat{y} \geq U i
\end{array}\right.
\end{aligned}
$$


Where $d_{\mathrm{i}}=$ desirability value

$L_{\mathrm{i}}$ is the lower limit of the response

$U_{\mathrm{i}}$ is the lower limit of the response

$T_{\mathrm{i}}$ is the target value

$\hat{y}$ is the lower limit of the response

The variable $\mathrm{s}$ is a constant that defines the shape of the desirability function. For $\mathrm{s}=1$, the desirability function is linear, similarly if $\mathrm{s}<1$, the desirability function is convex while for $\mathrm{s}$ $>1$ the desirability function is concave.

The composite desirability $(D C)$ is given by:

$$
D C=\left(d_{1} \times d_{2} \times d_{2} \times \ldots \times d_{n}\right)^{\frac{1}{n}}=\left(\prod_{i=1}^{n} d i\right)^{\frac{1}{n}}
$$

Where $\mathrm{n}$ is the number of variables.

If weights are assigned to $d_{\mathrm{i}}$, and the weights $w_{\mathrm{i}}$ is such that:

$$
w_{1}+w_{2}+w_{3} \ldots w_{n}=1
$$

Where $0<w_{i}<1$

$w_{\mathrm{i}}$ could be determined from principal component analysis, rank order centroid method, analytic hierarchical process (AHP), entropy etc.

$$
D C=\left(d_{1}^{w 1} \times d_{2}^{w 2} \times d_{3}^{w 3} \times \ldots \times d_{n}^{w n}\right)^{\frac{1}{n}}
$$

The weights $w_{\mathrm{i}}$ were obtained through analytical hierarchical process (AHP).

The AHP matrix obtained from the attributes is as shown in Table 6 .

Table 6: AHP matrix

\begin{tabular}{|l|l|l|l|l|l|l|l|l|}
\hline Criteria & $\begin{array}{l}\text { Tensile } \\
\text { Strengt } \\
\mathrm{h}\end{array}$ & $\begin{array}{l}\text { Specific } \\
\text { Strengt } \\
\mathrm{h}\end{array}$ & $\begin{array}{l}\text { Flexural } \\
\text { Strengt } \\
\mathrm{h}\end{array}$ & $\begin{array}{l}\text { Elongatio } \\
\mathrm{n}\end{array}$ & $\begin{array}{l}\text { Hardnes } \\
\mathrm{s}\end{array}$ & $\begin{array}{l}\text { Impact } \\
\text { Strengt } \\
\mathrm{h}\end{array}$ & $\begin{array}{l}\text { Modulu } \\
\mathrm{s}\end{array}$ & $\begin{array}{l}\text { Specific } \\
\text { Stiffnes } \\
\mathrm{s}\end{array}$ \\
\hline $\begin{array}{l}\text { Tensile } \\
\text { Strength }\end{array}$ & 1 & 1 & 2 & 3 & 4 & 5 & 6 & 6 \\
\hline Specific & 1 & 1 & 2 & 3 & 4 & 5 & 6 & 6 \\
\hline
\end{tabular}




\begin{tabular}{|l|l|l|l|l|l|l|l|l|}
\hline Strength & & & & & & & & \\
\hline $\begin{array}{l}\text { Flexural } \\
\text { Strength }\end{array}$ & $1 / 2$ & $1 / 2$ & 1 & 2 & 3 & 4 & 5 & 5 \\
\hline $\begin{array}{l}\text { Elongatio } \\
\mathrm{n}\end{array}$ & $1 / 3$ & $1 / 3$ & $1 / 2$ & 1 & 2 & 3 & 4 & 4 \\
\hline Hardness & $1 / 4$ & $1 / 4$ & $1 / 3$ & $1 / 2$ & 1 & 2 & 3 & 3 \\
\hline $\begin{array}{l}\text { Impact } \\
\text { Strength }\end{array}$ & $1 / 5$ & $1 / 5$ & $1 / 4$ & $1 / 3$ & $1 / 2$ & 1 & 2 & 2 \\
\hline Modulus & $1 / 6$ & $1 / 6$ & $1 / 5$ & $1 / 4$ & $1 / 3$ & $1 / 2$ & 1 & 1 \\
\hline $\begin{array}{l}\text { Specific } \\
\text { Stiffness }\end{array}$ & $1 / 6$ & $1 / 6$ & $1 / 5$ & $1 / 4$ & $1 / 3$ & $1 / 2$ & 1 & 1 \\
\hline
\end{tabular}

The priority vector obtained from the normalized eigenvector of the matrix in Table 6 is shown in Table 7.

Table 7: Priority vector matrix

\begin{tabular}{|l|l|l|l|l|l|l|l|l|l|}
\hline Criteria & $\begin{array}{l}\text { Tensile } \\
\text { Strength }\end{array}$ & $\begin{array}{l}\text { Specific } \\
\text { Strength }\end{array}$ & $\begin{array}{l}\text { Flexural } \\
\text { Strength }\end{array}$ & Elongation & Hardness & $\begin{array}{l}\text { Impact } \\
\text { Strength }\end{array}$ & Modulus & $\begin{array}{l}\text { Specific } \\
\text { Stiffness }\end{array}$ & Priority \\
\hline $\begin{array}{l}\text { Tensile } \\
\text { Strength }\end{array}$ & 1 & 1 & 2 & 3 & 4 & 5 & 6 & 6 & 0.260276 \\
\hline $\begin{array}{l}\text { Specific } \\
\text { Strength }\end{array}$ & 1 & 1 & 2 & 3 & 4 & 5 & 6 & 6 & 0.260276 \\
\hline $\begin{array}{l}\text { Flexural } \\
\text { Strength }\end{array}$ & $1 / 2$ & $1 / 2$ & 1 & 2 & 3 & 4 & 5 & 5 & \\
\hline Elongation & $1 / 3$ & $1 / 3$ & $1 / 2$ & 1 & 2 & 3 & 4 & 4 & 0.1714833 \\
\hline Hardness & $1 / 4$ & $1 / 4$ & $1 / 3$ & $1 / 2$ & 1 & 2 & 3 & 3 & 0.076688 \\
\hline $\begin{array}{l}\text { Impact } \\
\text { Strength }\end{array}$ & $1 / 5$ & $1 / 5$ & $1 / 4$ & $1 / 3$ & $1 / 2$ & 1 & 2 & 2 & \\
\hline Modulus & $1 / 6$ & $1 / 6$ & $1 / 5$ & $1 / 4$ & $1 / 3$ & $1 / 2$ & 1 & 1 & 0.030608 \\
\hline $\begin{array}{l}\text { Specific } \\
\text { Stiffness }\end{array}$ & $1 / 6$ & $1 / 6$ & $1 / 5$ & $1 / 4$ & $1 / 3$ & $1 / 2$ & 1 & 1 & \\
\hline
\end{tabular}

From the priority vector, the following weights $0.26135,0.26135,0.166618,0.108597$, $0.071001,0.046807$ and 0.032083 were assigned to tensile strength, specific strength, flexural strength, elongation, hardness, impact strength and specific stiffness respectively. The parameter settings for the optimization program were done according to Table 8 .

Table 8: Parameter settings

\begin{tabular}{|l|c|c|c|}
\hline \multicolumn{1}{|c|}{ Parameter } & Lower Limit & Upper Limit & Weight \\
\hline Inputs & & & \\
\hline \%Wt of baggase & 5 & 20 & \\
\hline \%Wt of Sponge gourd & 5 & 20 & \\
\hline Fiber size $(\mu \mathrm{m})$ & 150 & 600 & \\
\hline Responses & & & \\
\hline
\end{tabular}




\begin{tabular}{|l|c|c|c|}
\hline Tensile Strength & 50 & 250 & 0.260276 \\
\hline Specific Strength & 40 & 300 & 0.260276 \\
\hline Flexural Strength & 150 & 400 & 0.171214 \\
\hline Elongation & 10 & 20 & 0.114833 \\
\hline Hardness & 15 & 40 & 0.076688 \\
\hline Impact Strength & 15 & 40 & 0.050608 \\
\hline Modulus & 30 & 100 & 0.033053 \\
\hline Specific Stiffness & 73 & 400 & 0.033053 \\
\hline
\end{tabular}

\subsubsection{The Codes for the New Model}

The following pseudo codes shows the algorithm of the new desirability function criteria used to write the program to improve the desirability function implementation used for the multi-objective optimization program developed for this research.

// First Pseudo code

if $\mathrm{y}>=\mathrm{Li} \quad \& \& \quad \mathrm{y}<=\mathrm{Ui}$

$d(i)=1$

else

$d(i)=0$

end

// Second Pseudo code

if $\mathrm{y}>=\mathrm{T} 1 \quad \& \& \quad \mathrm{y}<=\mathrm{T} 2$

$$
d(i)=1
$$

elseif $y>T 2$

$d(i)=(U i-y) /(U i-T 2)$

elseif $y>U i$

$d(i)=0$

elseif $y<T 2$

$d(i)=(y-L i) /(T 1-L i)$

else 
$d(i)=0$

end

// Third Pseudo code used in NSGA-II

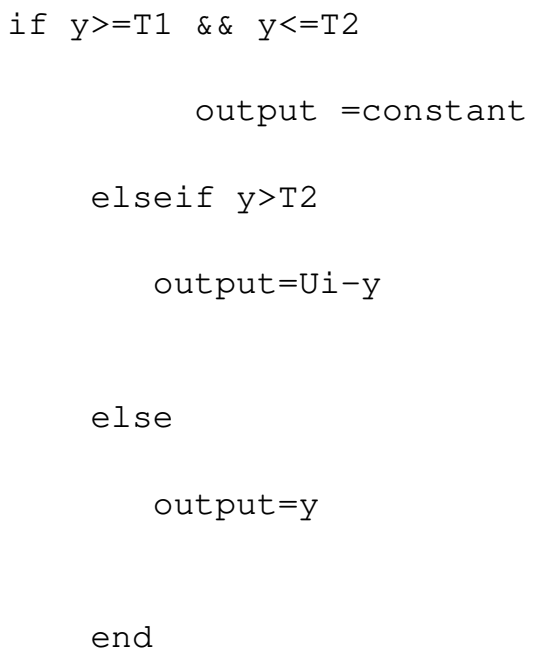




\subsubsection{Fuzzy Inference Coupled PSO Optimized Desirability Function}

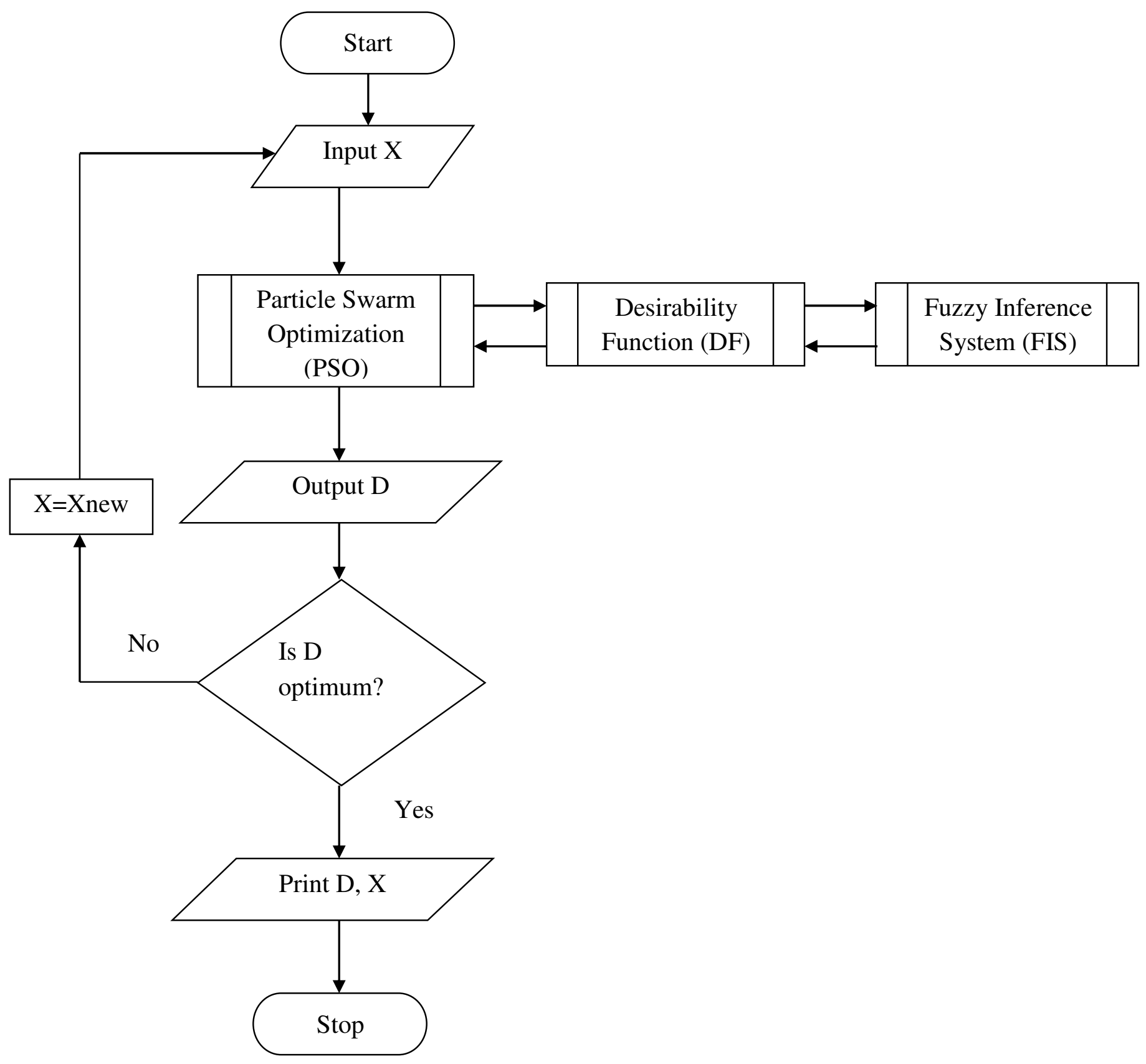

Figure 18: Fuzzy inference coupled PSO optimized desirability function program flowchart

Figure 18 shows the Fuzzy inference system coupled PSO optimized desirability function program flowchart. As shown in the flowchart, the PSO generates an input X, a 1 by 3 matrix containing the inputs namely: \%Wt of baggase, \%Wt of Sponge gourd and Fiber size $(\mu \mathrm{m})$. The PSO module contacts the desirability function (DF) module and sends $\mathrm{X}$ to the DF 
module. The DF module contacts the fuzzy inference system (FIS) module to obtain the outputs which corresponds to the inputs. The outputs are tensile strength, hardness, flexural strength, modulus, elongation and impact strength. The DF module makes use of the output of the FIS module to determine the desirability (D) of the output. The iteration continues until the optimum desirability (D) is reached.

We introduced the modifications to the desirability function model because of the elongation property of the golf club material whose desirability follows the graph in Figure 19.

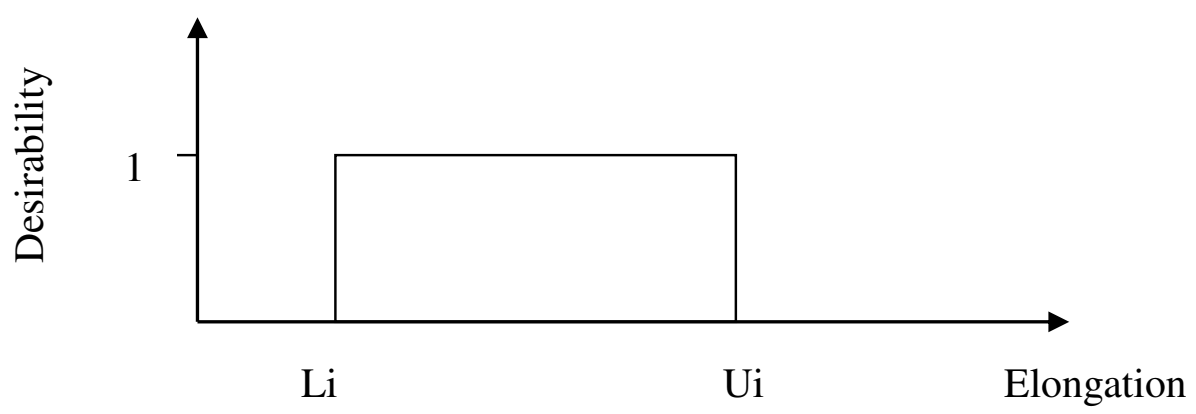

Figure 19: Desirability function graph for model 1

\subsubsection{Fuzzy Inference Coupled NSGA II Model}

Figure 20 shows the Fuzzy inference system coupled NSGA II program flowchart. As shown in the flowchart, the NSGA II module generates an input $\mathrm{X}$ consisting of the initial population of the input variables namely: \%Wt of baggase, \%Wt of Sponge gourd and Fiber size $(\mu \mathrm{m})$. The NSGA II module contacts the multi objective fitness function (FF) module and sends $\mathrm{X}$ to the FF module. The FF module contacts the fuzzy inference system (FIS) module to obtain the outputs which corresponds to the inputs. The outputs are as stated previously. The FF module makes use of the output of the FIS module to determine the fitness of the input. The iteration continues until the optimum Pareto front is reached. 


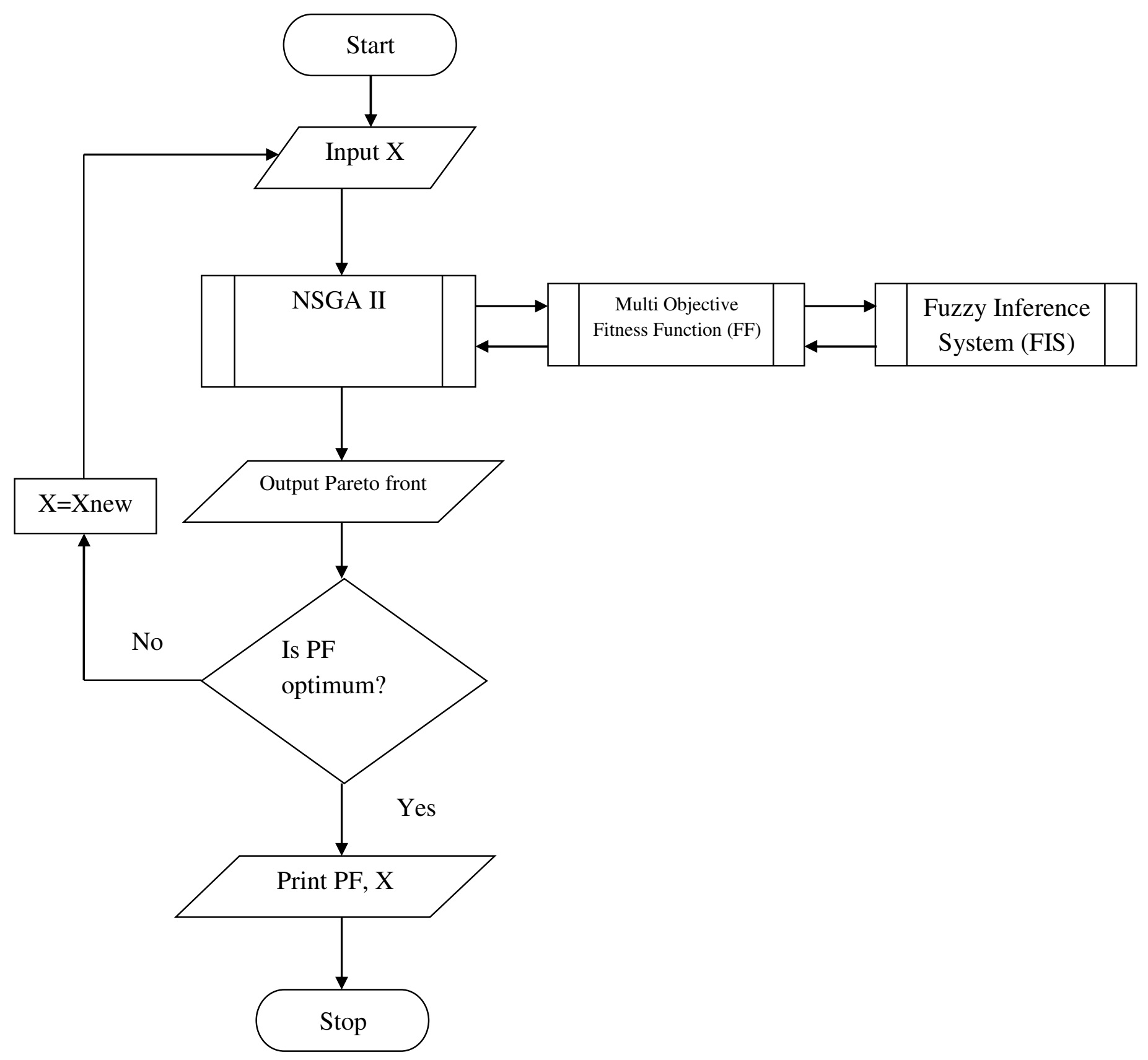

Figure 20: Fuzzy inference coupled NSGA II program flowchart

For the NSGA II algorithm, the elongation is modeled according to Figure 21. But in the NSGA II algorithm desirability is not used instead the values of the elongation are used to simulate desirability. The higher the values below the acceptable range the better. Values in 
the acceptable range are equally good. The lower the values above the acceptable range the better.

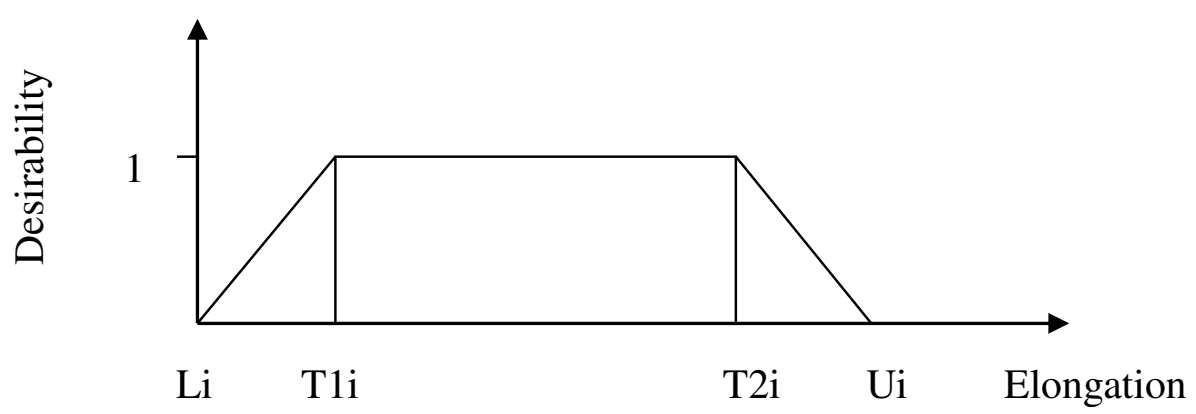

Figure 21: Desirability function graph for model 2

\subsection{Results and Discussion}

\subsection{Experimental Results}

Table 9 shows the results of the experiment conducted to obtain the mechanical properties of the composite as was designed in section 2.3. There were 27 experimental runs. The maximum value of the tensile strength was $80 \mathrm{MPa}$ while the minimum value was $26.5 \mathrm{MPa}$. The maximum value of the hardness was 52 while the minimum value was 10 . The maximum value of the flexural strength was $240 \mathrm{MPa}$ while the minimum value was $55 \mathrm{MPa}$. The maximum value of the modulus was $50 \mathrm{GPa}$ while the minimum value was $9 \mathrm{GPa}$. The maximum value of the elongation was 33 while the minimum value was 11 . The maximum value of the impact strength was 27.44 MPa while the minimum value was $19 \mathrm{MPa}$.

Table 9: Experimental results

\begin{tabular}{|c|c|c|c|c|c|c|c|c|c|}
\hline $\mathbf{S} / \mathbf{N}$ & $\begin{array}{l}\% \mathrm{Wt} \text { of } \\
\text { baggase }\end{array}$ & $\begin{array}{l}\% \mathrm{Wt} \\
\text { of } \\
\text { Sponge } \\
\text { gourd } \\
\end{array}$ & $\begin{array}{l}\text { Fiber } \\
\text { size } \\
(\mu \mathrm{m})\end{array}$ & $\begin{array}{l}\text { Tensile } \\
\text { strength } \\
\text { (MPa) }\end{array}$ & $\begin{array}{l}\text { Hardness } \\
\text { (Rockwell) }\end{array}$ & $\begin{array}{l}\text { Flexural } \\
\text { strength } \\
\text { (MPa) }\end{array}$ & $\begin{array}{l}\text { Modulus } \\
\text { (GPa) }\end{array}$ & Elongation & $\begin{array}{l}\text { Impact } \\
\text { Strength } \\
\text { (MPa) }\end{array}$ \\
\hline 1 & 5 & 5 & 600 & 32 & 17.9 & 90 & 10 & 12 & 19 \\
\hline 2 & 10 & 5 & 600 & 35 & 18.2 & 103 & 13.5 & 16 & 20.58 \\
\hline 3 & 20 & 5 & 600 & 42 & 18.4 & 110 & 15 & 18 & 22 \\
\hline 4 & 5 & 10 & 600 & 33 & 18.6 & 90 & 22 & 20 & 22.54 \\
\hline 5 & 10 & 10 & 600 & 33 & 20 & 85 & 25 & 22 & 21.56 \\
\hline 6 & 20 & 10 & 600 & 31 & 17.9 & 80 & 12 & 26 & 22 \\
\hline
\end{tabular}




\begin{tabular}{|c|c|c|c|c|c|c|c|c|c|}
\hline 7 & 5 & 20 & 600 & 33.6 & 41 & 98 & 18 & 33 & 19.6 \\
\hline 8 & 10 & 20 & 600 & 30 & 37 & 65 & 40 & 22 & 21.56 \\
\hline 9 & 20 & 20 & 600 & 27 & 49 & 55 & 45 & 21 & 19 \\
\hline 10 & 5 & 5 & 300 & 38 & 31 & 105 & 22.7 & 17 & 19.6 \\
\hline 11 & 10 & 5 & 300 & 45 & 28 & 115 & 24 & 16 & 20 \\
\hline 12 & 20 & 5 & 300 & 54 & 26 & 120 & 25 & 13 & 21.56 \\
\hline 13 & 5 & 10 & 300 & 39 & 25.5 & 95 & 14 & 13 & 21.56 \\
\hline 14 & 10 & 10 & 300 & 60 & 30 & 156 & 25 & 12 & 27.44 \\
\hline 15 & 20 & 10 & 300 & 41 & 33 & 110 & 22 & 12 & 21 \\
\hline 16 & 5 & 20 & 300 & 38 & 40 & 100 & 20 & 11 & 19.6 \\
\hline 17 & 10 & 20 & 300 & 27 & 38 & 80 & 13 & 13 & 26.46 \\
\hline 18 & 20 & 20 & 300 & 26.5 & 36 & 78 & 17 & 18 & 20.58 \\
\hline 19 & 5 & 5 & 150 & 49 & 48.5 & 135 & 26.5 & 12 & 20.58 \\
\hline 20 & 10 & 5 & 150 & 75 & 51 & 215 & 9 & 14 & 20.58 \\
\hline 21 & 20 & 5 & 150 & 63 & 51.5 & 170 & 47 & 12 & 20 \\
\hline 22 & 5 & 10 & 150 & 45 & 52 & 119 & 16 & 23 & 20.58 \\
\hline 23 & 10 & 10 & 150 & 80 & 20 & 240 & 50 & 12 & 20.58 \\
\hline 24 & 20 & 10 & 150 & 75 & 18 & 210 & 40 & 12 & 20.2 \\
\hline 25 & 5 & 20 & 150 & 68 & 18 & 202 & 41.5 & 12 & 20.58 \\
\hline 26 & 10 & 20 & 150 & 62 & 13 & 171 & 47.4 & 12 & 23.52 \\
\hline 27 & 20 & 20 & 150 & 45.5 & 10 & 140 & 20.4 & 20 & 21.56 \\
\hline
\end{tabular}

The values of the properties were within the range in the specifications of properties required for golf club materials as shown in Table 10.

Table 10: The properties of golf club materials

\begin{tabular}{|c|c|}
\hline Properties & Value \\
\hline 1. Tensile strength $(\mathrm{MPa})$ & $50-250$ \\
\hline 2. Flexural strength $(\mathrm{MPa})$ & $150-400$ \\
\hline 3. Hardness(Rockwell) & $15-40$ \\
\hline 4. Elongation (\%) & $10-20$ \\
\hline 5. Specific strength $(\mathrm{Nm} / \mathrm{kg})$ & $15-40$ \\
\hline 6. Specific stiffness $(\mathrm{Nm} / \mathrm{kg})$ & $20-50$ \\
\hline 7. Impact strength (MPa) & $15-40$ \\
\hline 8. Modulus ( GPa) & $30-100$ \\
\hline
\end{tabular}




\subsection{Fuzzy Logic Modelling Results}

Table 11 shows the experimental values and the fuzzy logic predicted values of the mechanical properties of the hybrid polymer composite material.

Table 11: Experimental results and fuzzy logic predictions

\begin{tabular}{|c|c|c|c|c|c|c|c|c|c|c|c|}
\hline $\begin{array}{c}\text { Tensile } \\
\text { strength }\end{array}$ & $\begin{array}{l}\text { Predicted } \\
\text { tensile } \\
\text { strength }\end{array}$ & Hardness & $\begin{array}{l}\text { Predicted } \\
\text { hardness }\end{array}$ & $\begin{array}{l}\text { Flexural } \\
\text { strength }\end{array}$ & $\begin{array}{l}\text { Predicted } \\
\text { flexural } \\
\text { strength }\end{array}$ & Modulus & $\begin{array}{l}\text { Predicted } \\
\text { Modulus }\end{array}$ & Elongation & $\begin{array}{l}\text { Predicted } \\
\text { Elongation }\end{array}$ & $\begin{array}{c}\text { Impact } \\
\text { Strength }\end{array}$ & $\begin{array}{c}\text { Predicted } \\
\text { impact } \\
\text { strength }\end{array}$ \\
\hline 95 & 94 & 17.9 & 18 & 90 & 90 & 10 & 10 & 12 & 12 & 19 & 19 \\
\hline 103.6 & 102 & 18.2 & 18 & 103 & 102 & 13.5 & 14 & 16 & 16 & 20.58 & 20.6 \\
\hline 120 & 118 & 18.4 & 18 & 110 & 110 & 15 & 14 & 18 & 18 & 22 & 22 \\
\hline 100 & 98 & 18.6 & 18 & 90 & 90 & 22 & 22 & 20 & 20 & 22.54 & 22.6 \\
\hline 100 & 98 & 20 & 20 & 85 & 86 & 25 & 24 & 22 & 22 & 21.56 & 21.6 \\
\hline 95 & 94 & 17.9 & 18 & 80 & 78 & 12 & 12 & 26 & 26 & 22 & 22 \\
\hline 102 & 102 & 41 & 40 & 98 & 98 & 18 & 18 & 33 & 32 & 19.6 & 19.6 \\
\hline 70 & 70 & 37 & 36 & 65 & 70 & 40 & 40 & 22 & 22 & 21.56 & 21.6 \\
\hline 60 & 58 & 49 & 49 & 55 & 54 & 45 & 44 & 21 & 20 & 19 & 19 \\
\hline 107 & 106 & 31 & 30 & 105 & 106 & 22.7 & 22 & 17 & 16 & 19.6 & 19.6 \\
\hline 130 & 130 & 28 & 28 & 115 & 114 & 24 & 24 & 16 & 16 & 20 & 20 \\
\hline 150 & 150 & 26 & 26 & 120 & 118 & 25 & 24 & 13 & 12 & 21.56 & 21.6 \\
\hline 110 & 110 & 25.5 & 26 & 95 & 94 & 14 & 14 & 13 & 12 & 21.56 & 21.6 \\
\hline 170 & 170 & 30 & 30 & 156 & 154 & 25 & 32 & 12 & 12 & 27.44 & 27.4 \\
\hline 115 & 114 & 33 & 32 & 110 & 110 & 22 & 22 & 12 & 12 & 21 & 21 \\
\hline 110 & 110 & 40 & 40 & 100 & 98 & 20 & 20 & 11 & 10 & 19.6 & 19.6 \\
\hline 83 & 82 & 38 & 38 & 80 & 78 & 13 & 12 & 13 & 12 & 26.46 & 26.4 \\
\hline 81 & 82 & 36 & 36 & 78 & 78 & 17 & 16 & 18 & 18 & 20.58 & 20.6 \\
\hline 138 & 148 & 48.5 & 48 & 135 & 136 & 26.5 & 27 & 12 & 12 & 20.58 & 20.6 \\
\hline 216.6 & 216 & 51 & 50 & 215 & 216 & 49 & 50 & 14 & 14 & 20.58 & 20.6 \\
\hline 180 & 182 & 51.5 & 52 & 170 & 170 & 47 & 46 & 12 & 12 & 20 & 20 \\
\hline 121 & 122 & 52 & 52 & 119 & 118 & 16 & 16 & 23 & 22 & 20.58 & 20.6 \\
\hline 248 & 246 & 20 & 20 & 240 & 238 & 50 & 50 & 12 & 12 & 20.58 & 20.6 \\
\hline 220 & 220 & 18 & 18 & 210 & 212 & 40 & 40 & 12 & 12 & 20.2 & 20.2 \\
\hline 206 & 204 & 18 & 18 & 202 & 199 & 41.5 & 42 & 12 & 12 & 20.58 & 20.6 \\
\hline 181 & 182 & 13 & 12 & 171 & 170 & 47.4 & 48 & 12 & 12 & 23.52 & 23.4 \\
\hline 144 & 142 & 10 & 9.9 & 140 & 138 & 20.4 & 20 & 20 & 20 & 21.56 & 21.6 \\
\hline
\end{tabular}

Table 12 shows the correlation coefficients between the experimental values and fuzzy logic predicted values shown in Table 11. As shown in Table 12, flexural strength has the highest $R$ value of 0.9912 while impact strength had the lowest $R$ value of 0.9529 . 
Table 12: Statistics of fuzzy logic predictions of responses

\begin{tabular}{|l|c|}
\hline Fuzzy Logic Predictions Vs Experimental Data & R \\
\hline Tensile Strength & 0.9912 \\
\hline Hardness & 0.9657 \\
\hline Flexural Strength & 0.9922 \\
\hline Modulus & 0.9857 \\
\hline Elongation & 0.9637 \\
\hline Impact Strength & 0.9529 \\
\hline
\end{tabular}

\subsection{Optimization Results}

After running the modified NSGA II algorithm, the process decision variables corresponding to each of the Pareto optimal solutions is shown in Table 13. A closer look at Table 13 it should be observed that only 5 of the parameters on the Pareto front have desirability values above zero. It means that the other process variables on the front have one or more mechanical properties that fail to meet the requirements for golf club application as shown in Table 10.

Table 13: Process decision variables corresponding to each of the Pareto optimal solutions

\begin{tabular}{|c|r|r|l|l|l|r|r|r|r|r|r|l|}
\hline S/N & \% Bg & \%SG & FS & TS & H & FS & Mod & El & IS & Sstr & Sstif & Des \\
\hline 1 & 5.00 & 5.00 & 150.00 & 53.63 & 39.37 & 160.50 & 26.58 & 15.98 & 20.61 & 33.52 & 16.61 & 0.00 \\
\hline 2 & 13.80 & 10.00 & 168.03 & 81.01 & 19.98 & 237.98 & 50.01 & 11.97 & 20.63 & 50.63 & 31.26 & 0.83 \\
\hline 3 & 12.59 & 10.00 & 168.03 & 81.00 & 19.98 & 237.99 & 49.99 & 11.99 & 20.61 & 50.63 & 31.25 & 0.83 \\
\hline 4 & 10.00 & 15.98 & 202.93 & 27.40 & 37.94 & 78.00 & 11.87 & 11.95 & 26.36 & 17.13 & 7.42 & 0.00 \\
\hline 5 & 13.67 & 10.00 & 168.04 & 81.02 & 19.99 & 237.99 & 50.00 & 11.98 & 20.63 & 50.64 & 31.25 & 0.83 \\
\hline 6 & 10.00 & 10.17 & 281.57 & 58.09 & 30.51 & 150.19 & 30.72 & 11.99 & 27.33 & 36.31 & 19.20 & 0.00 \\
\hline 7 & 9.75 & 16.58 & 504.17 & 32.34 & 38.16 & 85.99 & 25.75 & 25.50 & 20.61 & 20.21 & 16.09 & 0.00 \\
\hline 8 & 15.75 & 17.41 & 512.55 & 27.19 & 48.00 & 54.00 & 44.01 & 19.98 & 18.97 & 16.99 & 27.51 & 0.00 \\
\hline 9 & 12.96 & 16.31 & 502.64 & 28.90 & 41.70 & 58.00 & 42.00 & 21.00 & 20.28 & 18.06 & 26.25 & 0.00 \\
\hline 10 & 10.00 & 15.87 & 156.49 & 63.00 & 12.01 & 170.00 & 48.01 & 11.99 & 23.40 & 39.38 & 30.00 & 0.00 \\
\hline 11 & 15.43 & 16.70 & 503.82 & 27.37 & 47.85 & 54.00 & 44.12 & 19.95 & 18.96 & 17.10 & 27.57 & 0.00 \\
\hline 12 & 14.83 & 16.17 & 506.36 & 27.85 & 45.14 & 55.67 & 43.08 & 20.36 & 19.51 & 17.40 & 26.93 & 0.00 \\
\hline 13 & 10.00 & 12.84 & 247.91 & 42.33 & 34.39 & 112.41 & 21.14 & 11.99 & 26.83 & 26.46 & 13.21 & 0.00 \\
\hline 14 & 5.13 & 10.48 & 153.63 & 51.99 & 37.04 & 143.46 & 24.68 & 21.51 & 20.82 & 32.50 & 15.42 & 0.00 \\
\hline 15 & 9.94 & 11.99 & 172.37 & 71.88 & 17.17 & 205.80 & 47.53 & 12.66 & 21.91 & 44.93 & 29.71 & 0.79 \\
\hline 16 & 14.85 & 15.86 & 270.90 & 27.07 & 36.07 & 78.00 & 15.78 & 17.67 & 20.91 & 16.92 & 9.86 & 0.00 \\
\hline 17 & 15.43 & 16.71 & 503.81 & 27.37 & 47.85 & 54.00 & 44.12 & 19.95 & 18.96 & 17.10 & 27.57 & 0.00 \\
\hline 18 & 9.91 & 9.94 & 177.24 & 75.51 & 22.66 & 224.61 & 45.77 & 13.03 & 20.61 & 47.20 & 28.61 & 0.82 \\
\hline
\end{tabular}


Table 14 show the optimal solution obtained after running the modified desirability function program whose flowchart is depicted in Figure 18. The optimum desirability is 0.8418 for three runs of the optimization algorithm. The unique thing about the desirability function model is the modification introduced in Equation 15 to model the elongation property.

Designers usually model such properties by adopting the larger the better or the nominal the best model assumption. If the larger the better model (Equation 9) was adopted for elongation, the result shown in Table 15 was obtained. Similarly, if the nominal the best model (Equations 11-14) was adopted the results shown in Table 16 was obtained. It is clear that the optimum properties obtained from the modified model was better than what was obtained by not modifying the models because the desirability values in Table 14 are clearly higher than those in Tables 15 and 16.

Table 14: Optimum solutions obtained using the modified desirability function

\begin{tabular}{|c|c|c|c|c|c|c|c|c|c|c|c|r|}
\hline Run & Bg\% & SG\% & Fs & TS & H & FI & Mod & El & Is & Sstr & Sstif & Desirability \\
\hline 1 & 10 & 6.62 & 150.00 & 78.16 & 39.33 & 227.97 & 49.99 & 12.94 & 20.61 & 48.85 & 24.58 & 0.841761 \\
\hline 2 & 10 & 6.62 & 150.00 & 78.16 & 39.33 & 227.97 & 49.99 & 12.94 & 20.61 & 48.85 & 24.58 & 0.841761 \\
\hline 3 & 10 & 6.62 & 150.00 & 78.16 & 39.33 & 227.97 & 49.99 & 12.94 & 20.61 & 48.85 & 24.58 & 0.841761 \\
\hline
\end{tabular}

A comparison of the optimum mechanical properties in Table 14 and the mechanical properties of golf club materials shown in Table 10 shows that the mechanical properties of the optimized composite material conforms excellently well to the specifications of materials for golf club applications.

Table 15: Optimum solutions obtained using the larger the better assumption

\begin{tabular}{|r|r|c|c|c|c|c|c|c|c|c|c|r|}
\hline Run & Bg\% & SG\% & Fs & TS & H & FI & Mod & El & Is & Sstr & Sstif & Desirability \\
\hline 1 & 10 & 5.52 & 150.00 & 78.01 & 40.00 & 227.29 & 49.99 & 12.99 & 20.61 & 48.76 & 25.00 & 0.8186237 \\
\hline 2 & 10 & 5.52 & 150.00 & 78.01 & 40.00 & 227.29 & 49.99 & 12.99 & 20.61 & 48.76 & 25.00 & 0.8186237 \\
\hline 3 & 10 & 5.52 & 150.00 & 78.01 & 40.00 & 227.29 & 49.99 & 12.99 & 20.61 & 48.76 & 25.00 & 0.8186237 \\
\hline
\end{tabular}

Table 16: Optimum solutions obtained using the nominal the best assumption

\begin{tabular}{|r|r|c|c|c|c|c|c|c|c|c|c|c|}
\hline Run & Bg\% & SG\% & Fs & TS & H & FI & Mod & El & Is & Sstr & Sstif & Desirability \\
\hline 1 & 10 & 5.523 & 150.00 & 78.01 & 39.99 & 227.30 & 49.99 & 12.99 & 20.61 & 48.76 & 25.00 & 0.83175985 \\
\hline 2 & 10 & 5.523 & 150.00 & 78.01 & 39.99 & 227.30 & 49.99 & 12.99 & 20.61 & 48.76 & 25.00 & 0.83175985 \\
\hline 3 & 10 & 5.523 & 150.00 & 78.01 & 39.99 & 227.30 & 49.99 & 12.99 & 20.61 & 48.76 & 25.00 & 0.83175985 \\
\hline
\end{tabular}




\subsection{Conclusion}

The utility of smart systems based on artificial intelligence in prediction and multi objective optimization of hybrid polymer composite material developed from sponge gourd and bagasse and epoxy resin has been shown in this study. The study has equally shown that fuzzy logic is an excellent tool in modeling non linear relationships which often occurs between input (s) and output (s) variables in materials development and processing. The modified desirability function and NSGA II algorithm represents important contributions to multi criteria decision analysis and its applications to engineering.

The complex system developed by linking desirability function to PSO coupled to a fuzzy logic model has extended the frontier of artificial intelligence applications in building smart systems that would create high quality optimized engineering products. The same applies to the modified NSGA II algorithm coupled with fuzzy logic model as its fitness function.

\section{Declaration of interests}

The authors declare that they have no known competing financial interests or personal relationships that could have appeared to influence the work reported in this paper.

\section{References}

[1] Sinha, A. K., Narang, H. K., \& Bhattacharya, S. (2020). A fuzzy logic approach for modelling and prediction of mechanical properties of hybrid abaca-reinforced polymer composite. Journal of the Brazilian Society of Mechanical Sciences and Engineering, 42, 111.

[2] Nwobi-Okoye, C.C. and Umeonyiagu, I.E. (2016). Modelling the Effects of Petroleum Product Contaminated Sand on the Compressive Strength of Concretes Using Fuzzy Logic and Artificial Neural Networks: African Journal of Science, Technology, Innovation and Development, 8:3, 264-274.

[3] Atuanya, C.U., Government, M.R., Nwobi-Okoye, C.C., Onukwuli, O.D., 2014. Predicting the Mechanical Properties of Date Palm Wood Fibre-Recycled Low Density Polyethylene Composite Using Artificial Neural Network, International Journal of Mechanical and Materials Engineering, 7(1):1-20.

[4] Sirdesai, N. N., Singh, A., Sharma, L. K., Singh, R., \& Singh, T. N. (2019). Development of novel methods to predict the strength properties of thermally treated sandstone using statistical and soft-computing approach. Neural Computing and Applications, 31(7), 28412867. 
[5] Lopes, H., Silva, S. P., \& Machado, J. (2021). Application of artificial neural networks to predict mechanical behaviour of cork-rubber composites. Neural Computing and Applications, 1-10.

[6] Nazari, A., Hajiallahyari, H., Rahimi, A., Khanmohammadi, H., \& Amini, M. (2019). Prediction compressive strength of Portland cement-based geopolymers by artificial neural networks. Neural Computing and Applications, 31(2), 733-741.

[7] Devadiga, U., Poojary, R. K. R., \& Fernandes, P. (2019). Artificial neural network technique to predict the properties of multiwall carbon nanotube-fly ash reinforced aluminium composite. Journal of Materials Research and Technology, 8(5), 3970-3977.

[8] Nwobi-Okoye, C.C., Ochieze, B. Q. \& Okiy, S. (2019a). Multi-Objective Optimization and Modeling of Age Hardening Process Using ANN, ANFIS and Genetic Algorithm: Results from Aluminum Alloy A356/Cow Horn Particulate Composite. Journal of Materials Research and Technology. https://doi.org/10.1016/j.jmrt.2019.01.031

[9] Nwobi-Okoye, C.C., Okonji, P.C. \& Okiy, S. (2019b). Optimization of Dry Compressive Strength of Groundnut Shell Ash Particles (GSAp) and Ant Hill Bonded Foundry Sand Using ANN and Genetic Algorithm. Cogent Engineering, 2019, 6: 1681055.

[10] Umeonyiagu, I.E. and Nwobi-Okoye, C.C. (2019). Modelling and Multi Objective Optimization of Bamboo Reinforced Concrete Beams Using ANN and Genetic Algorithms. European Journal of Wood and Wood Products, 2019 (77):931-947.

[11] Nwobi-Okoye, C.C. \& Uzochukwu, C.U. (2020). RSM and ANN modeling for production of Al 6351/ Egg Shell Reinforced Composite: Multi objective optimization using genetic algorithm. Materials Today Communications. https://doi.org/10.1016/j.mtcomm.2019.100674

[12] Nwobi-Okoye, C.C., Anyichie, M.K. \& Atuanya, C.U. (2020). RSM and ANN modeling for production of Newbouldia Laevies Fibre and Recycled High Density Polyethylene Composite: Multi objective optimization using genetic algorithm. Fibers and Polymers, 21(4): 898-909.

[13] Nwobi-Okoye, C. C. \& Ochieze, B. Q. (2018). Age Hardening Process Modeling and Optimization of Aluminum Alloy A356/Cow Horn Particulate Composite for Brake Drum Application Using RSM, ANN and Simulated Annealing. Defence Technology, 14(2018), 336-345. https://doi.org/10.1016/j.dt.2018.04.001

[14] Nwobi-Okoye, C.C., Umeonyiagu, I.E., (2015). Predicting the Flexural Strength of Concretes Made with Granite from Eastern Nigeria Using Multi-Layer Perceptron Networks. Journal of the Nigerian Association of Mathematical Physics, 29(2015): 55-64.

[15] Nwobi-Okoye, C.C., Umeonyiagu, I.E., 2013. Predicting the Compressive Strength of Concretes Made with Unwashed Gravel from Eastern Nigeria Using Artificial Neural Networks. Nigerian Journal of Technological Research, 8(2):22-29. 
[16] Nwobi-Okoye, C.C., Umeonyiagu, I.E., Nwankwo, C.G., 2013. Predicting the Compressive Strength of Concretes Made with Granite from Eastern Nigeria Using Artificial Neural Networks. Nigerian Journal of Technology (NIJOTECH), 32(1):13-21.

[17] Umeonyiagu, I.E. and Nwobi-Okoye, C.C. (2015a). Predicting Flexural Strength of Concretes Incorporating River Gravel Using Multi Multi-Layer Perceptron Networks: A Case Study of Eastern Nigeria. Nigerian Journal of Technology (NIJOTECH), 34(1):12-20.

[18] Umeonyiagu, I.E. and Nwobi-Okoye, C.C. (2015b). Modelling Compressive Strength Of Concretes Incorporating Termite Mound Soil Using Multi-Layer Perceptron Networks: A Case Study Of Eastern Nigeria. International Journal of Research and Reviews in Applied Sciences, 24(1):19-30.

[19] Umeonyiagu, I.E. and Nwobi-Okoye, C.C. (2013). Predicting the Compressive Strength of Concretes Made with Washed Gravel from Eastern Nigeria Using Artificial Neural Networks. Journal of the Nigerian Association of Mathematical Physics, 23: 559-558.

[20] Chowdhury, M. A., Shuvho, B. A., Debnath, U. K., \& Nuruzzaman, D. M. (2019). Prediction and optimization of erosion rate of carbon fiber-reinforced ebonite using fuzzy logic. Journal of Testing and Evaluation, 47(2), 1244-1258.

[21] Tarasov, V., Tan, H., Jarfors, A. E., \& Seifeddine, S. (2020). Fuzzy logic-based modelling of yield strength of as-cast A356 alloy. Neural Computing and Applications, 32(10), 5833-5844.

[22] Aamir, M., Tu, S., Tolouei-Rad, M., Giasin, K., \& Vafadar, A. (2020). Optimization and modeling of process parameters in multi-hole simultaneous drilling using taguchi method and fuzzy logic approach. Materials, 13(3), 680.

[23] Chibueze, I.G. (2021) Evaluation of Natural Fiber Reinforced Hybrid Composite for Sport Application (Golf Club). MEng Dissertation, Nnamdi Azikiwe University, Nigeria. 